University of Tennessee Health Science Center

UTHSC Digital Commons

\title{
The Effect of Progesterone Only Contraception on the Accuracy of Cervical Cytologic interpretation
}

\author{
Michelle Reneé Collins \\ University of Tennessee Health Science Center
}

Follow this and additional works at: https://dc.uthsc.edu/dissertations

Part of the Diagnosis Commons

\section{Recommended Citation}

Collins, Michelle Reneé, "The Effect of Progesterone Only Contraception on the Accuracy of Cervical Cytologic interpretation" (2012). Theses and Dissertations (ETD). Paper 46. http://dx.doi.org/10.21007/ etd.cghs.2012.0055.

This Dissertation is brought to you for free and open access by the College of Graduate Health Sciences at UTHSC Digital Commons. It has been accepted for inclusion in Theses and Dissertations (ETD) by an authorized administrator of UTHSC Digital Commons. For more information, please contact jwelch30@uthsc.edu. 


\title{
The Effect of Progesterone Only Contraception on the Accuracy of Cervical Cytologic interpretation
}

\author{
Abstract \\ Abstract Introduction: Papanicolaou screening is the standard of care for the detection of abnormal \\ cervical cells. Early detection and treatment of cervical neoplasia depends on the accurate interpretation \\ of the cytologic sample. Diagnosis of dysplasia is made by histology interpretation to confirm the results \\ of cytology screening. Cervical cells are susceptible to change as a result of hormonal exposure, and this \\ has the potential to affect cytologic interpretation. Cervical cells may be exposed to exogenous \\ progesterone if the woman uses injectable depot medroxyprogesterone acetate or a progesterone \\ intrauterine device. Previous study results have been inconsistent regarding the effect of progesterone on \\ relationship between cytology and histology interpretation. The purpose of this exploratory study was to \\ examine the accuracy of cervical cytologic findings in women who were using either one of two forms of \\ progesterone only contraception, depot medroxyprogesterone acetate injection or the progesterone IUD, \\ as compared to women who either used a non-hormonal form of contraception or no contraception. \\ Accuracy, for the purposes of this study, was defined as the association between cytology interpretation \\ and histology interpretation. A secondary purpose of the exploratory study was to investigate whether the \\ length of time of progesterone exposure had an effect on the association between cytologic and \\ histologic findings. Methods: A de-identified synthetic derivative database was used for this study in \\ which cytology and histology results from 180 women were analyzed. Three groups were mined from the \\ database: a group using the progesterone releasing intrauterine device (IUD, $N=35$ ), a group using the \\ injectable depot medroxyprogesterone $(\mathrm{N}=73)$, and a control group of women who used either no \\ contraception or non-hormonal contraception $(\mathrm{N}=72)$. Cytology and histology were analyzed for \\ associations as well as for sensitivity and specificity. Chi square analysis and logistic regression were the \\ statistical methods used to test the associations. Results: Cytology and histology results were collapsed \\ into low grade/high grade categories. There was a significant association between cytology and histology \\ findings $(p=.008)$ among the total group $(N=180)$. Among subgroups analyzed from low grade/high \\ grade perspective, a significant relationship was found between cytology and histology among women \\ who had no progesterone exposure $(p=.019)$ and those using the progesterone IUD $(p=.019)$. However, \\ there was not a significant association between cytology and histology findings in progesterone injection \\ users $(p=.790)$. Thus a new outcome variable was then applied for more precise analysis in which each \\ cytology/histology relationship was labeled as agree, false negative or false positive. Using the new \\ outcome variable (false negative, false positive or agree) there was no difference in the association of \\ cytology and histology by progesterone exposure. Logistic regression revealed no relationship between \\ length of time of progesterone exposure and accuracy of cytologic interpretation. Conclusion: Although \\ our exploratory study was significantly underpowered, findings suggest that the subjects in this study who \\ used either the progesterone IUD or injection had no difference in association of their cytology to \\ histology findings compared to women who had no progesterone exposure. What can be derived from the \\ study is a basis for comparing varied progesterone delivery systems, as well as format for repetition of a \\ similar study in a multi center, multi site study. There are several other forms of progesterone (implant \\ and oral progesterone formulations) which were not included in this study which may affect the \\ association between cytology and histology results. Further investigation is warranted.
}

\section{Document Type}

Dissertation

\section{Degree Name}

Doctor of Philosophy (PhD) 


\section{Program}

Nursing

Research Advisor

Wendy M. Likes, PhD, DNSc

\section{Keywords}

Cervical Colposcopy Dysplasia Papanicolaou Progesterone Intrauterine device

\section{Subject Categories}

Analytical, Diagnostic and Therapeutic Techniques and Equipment | Diagnosis | Medicine and Health Sciences 
THE EFFECT OF PROGESTERONE ONLY CONTRACEPTION ON THE ACCURACY OF CERVICAL CYTOLOGIC INTERPRETATION

\author{
A Dissertation \\ Presented for \\ The Graduate Studies Council \\ The University of Tennessee \\ Health Science Center \\ In Partial Fulfillment \\ Of the Requirements for the Degree \\ Doctor of Philosophy \\ From The University of Tennessee
}

By

Michelle Reneé Collins

May 2012 
Copyright (C) 2012 by Michelle Reneé Collins. All rights reserved. 


\section{DEDICATION}

This dissertation is dedicated to my family. I want to thank my husband Richard, and my sons, Richard and Andrew, without whose constant love and support I could not have made this journey. 


\section{ACKNOWLEDGEMENTS}

I would like to thank both my current advisor, Dr. Wendy Likes, and my former co-advisor, Dr. Ann Cashion, for their guidance and mentorship. I would also like to thank my other committee members, Drs. Michael Carter, Jeffry Gordon, and Cheryl Stegbauer for their guidance and support. An expression of appreciation is extended to Ms. Anna Emily for her editorial support, and Dr. Irene Feurer for her statistical expertise. 


\begin{abstract}
Introduction: Papanicolaou screening is the standard of care for the detection of abnormal cervical cells. Early detection and treatment of cervical neoplasia depends on the accurate interpretation of the cytologic sample. Diagnosis of dysplasia is made by histology interpretation to confirm the results of cytology screening. Cervical cells are susceptible to change as a result of hormonal exposure, and this has the potential to affect cytologic interpretation. Cervical cells may be exposed to exogenous progesterone if the woman uses injectable depot medroxyprogesterone acetate or a progesterone intrauterine device. Previous study results have been inconsistent regarding the effect of progesterone on relationship between cytology and histology interpretation. The purpose of this exploratory study was to examine the accuracy of cervical cytologic findings in women who were using either one of two forms of progesterone only contraception, depot medroxyprogesterone acetate injection or the progesterone IUD, as compared to women who either used a non-hormonal form of contraception or no contraception. Accuracy, for the purposes of this study, was defined as the association between cytology interpretation and histology interpretation. A secondary purpose of the exploratory study was to investigate whether the length of time of progesterone exposure had an effect on the association between cytologic and histologic findings.
\end{abstract}

Methods: A de-identified synthetic derivative database was used for this study in which cytology and histology results from 180 women were analyzed. Three groups were mined from the database: a group using the progesterone releasing intrauterine device (IUD, $\mathrm{N}=35$ ), a group using the injectable depot medroxyprogesterone $(\mathrm{N}=73)$, and a control group of women who used either no contraception or non-hormonal contraception $(\mathrm{N}=72)$. Cytology and histology were analyzed for associations as well as for sensitivity and specificity. Chi square analysis and logistic regression were the statistical methods used to test the associations.

Results: Cytology and histology results were collapsed into low grade/high grade categories. There was a significant association between cytology and histology findings $(p=.008)$ among the total group $(\mathrm{N}=180)$. Among subgroups analyzed from low grade/high grade perspective, a significant relationship was found between cytology and histology among women who had no progesterone exposure $(p=.019)$ and those using the progesterone IUD $(p=.019)$. However, there was not a significant association between cytology and histology findings in progesterone injection users $(p=.790)$. Thus a new outcome variable was then applied for more precise analysis in which each cytology/histology relationship was labeled as agree, false negative or false positive. Using the new outcome variable (false negative, false positive or agree) there was no difference in the association of cytology and histology by progesterone exposure. Logistic regression revealed no relationship between length of time of progesterone exposure and accuracy of cytologic interpretation.

Conclusion: Although our exploratory study was significantly underpowered, findings suggest that the subjects in this study who used either the progesterone IUD or 
injection had no difference in association of their cytology to histology findings compared to women who had no progesterone exposure. What can be derived from the study is a basis for comparing varied progesterone delivery systems, as well as format for repetition of a similar study in a multi center, multi site study. There are several other forms of progesterone (implant and oral progesterone formulations) which were not included in this study which may affect the association between cytology and histology results. Further investigation is warranted. 


\section{TABLE OF CONTENTS}

Chapter 1. INTRODUCTION ...............................................................................1

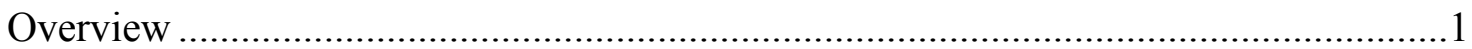

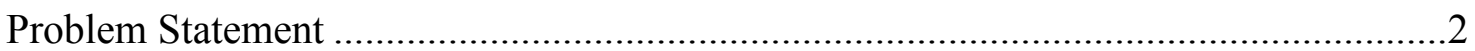

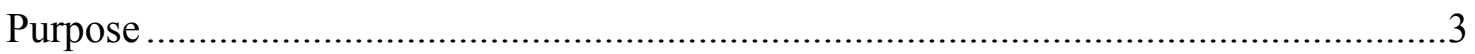

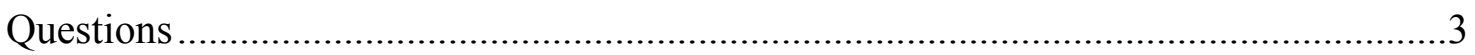

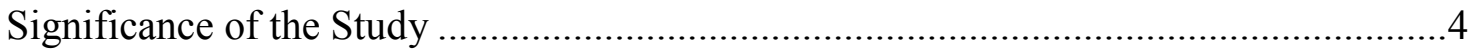

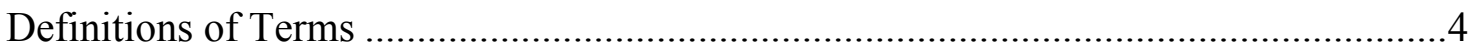

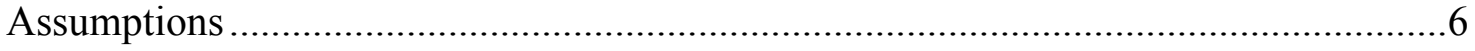

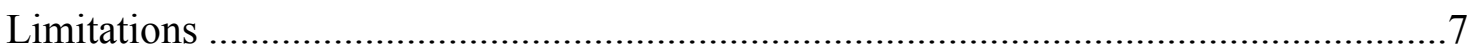

Conceptual Framework ……………………….............................................

Chapter 2. REVIEW OF LITERATURE..........................................................................9

Overview of Squamous Metaplasia and Human Papilloma Virus as Etiology of

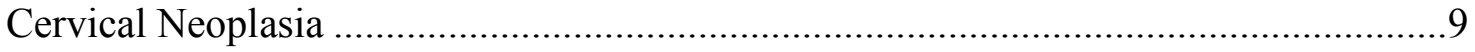

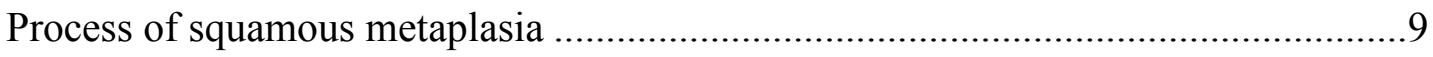

Development of squamous intraepithelial abnormality............................................10

Development of glandular abnormalities .............................................................10

HPV as etiologic agent in neoplastic development .................................................11

Cytopathologic and Histopathologic Characteristics of Cellular Lesions and

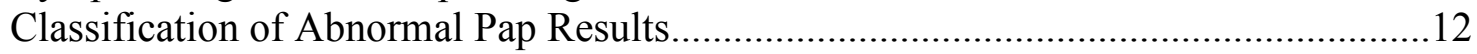

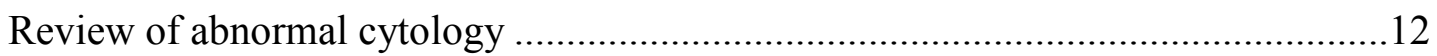

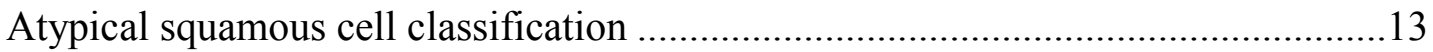

Low grade squamous intraepithelial lesion (LSIL) classification ................................13

High grade squamous intraepithelial lesion (HSIL) classification................................14

Invasive squamous cell neoplasia classification......................................................14

Atypical glandular cell classification .....................................................................14

ASC-H and LSIL-H classification......................................................................14

Description of cervical intraepithelial lesions .............................................................15

Cervical Neoplasia and Combined Hormonal Contraceptive Use .................................15

Cervical Neoplasia and Progesterone Use …………................................................18

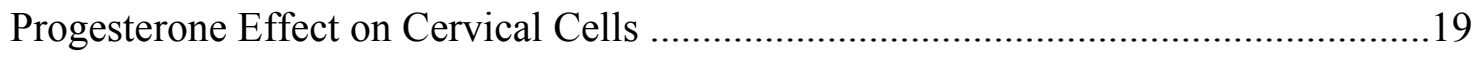

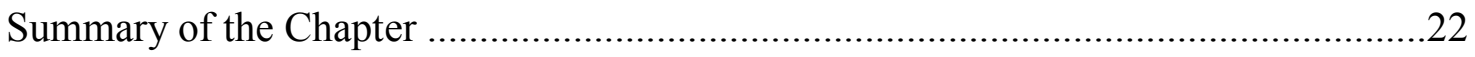

Chapter 3. METHODOLOGY .......................................................................................23

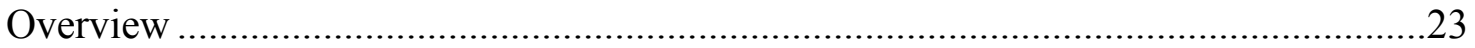

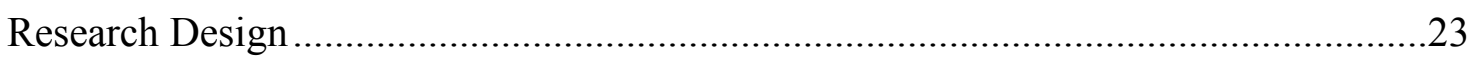

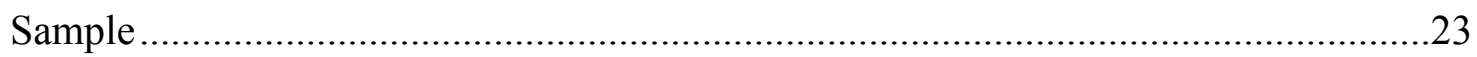

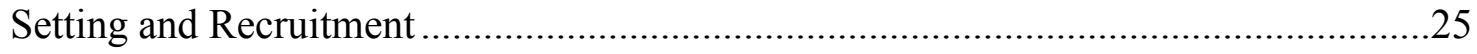

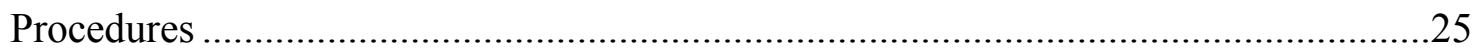




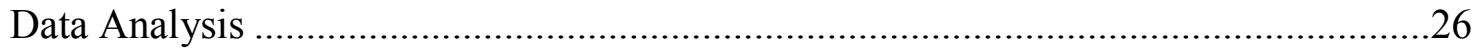

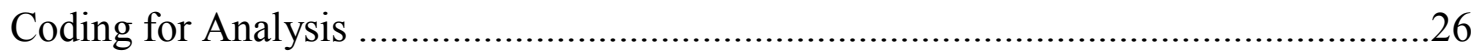

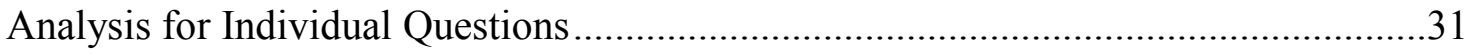

Chapter 4. RESULTS .........................................................................................................32

Research Question 1: What Are the Characteristics (Demographic, Gynecologic and Smoking History) of Four Groups of Women Who Have Abnormal Cytologic

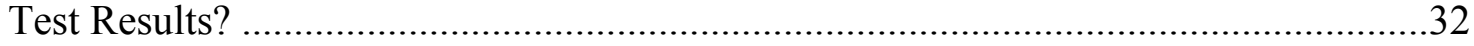

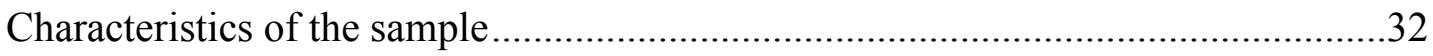

Frequency of cytologic and histologic abnormalities.................................................32

Research Question 2: What is the Relationship between Cytology and Histology in Four Groups of Women with Abnormal Cytology Results? .............................................38

Research Question 3: Is There a Difference in the Relationship between Cytology and Histology in Four Groups of Women with Abnormal Cytology Results?....

Research Question 4: Is There a Difference in the Relationship between Cytology and Histology, by Length of Time Using Either Depot Medroxyprogesterone

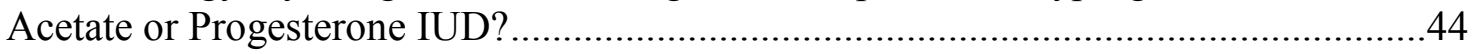

Post Hoc Power Analyses ......................................................................................48

Chapter 5. DISCUSSION....................................................................................50

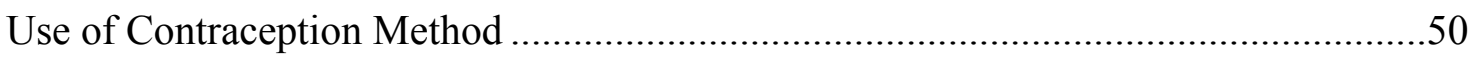

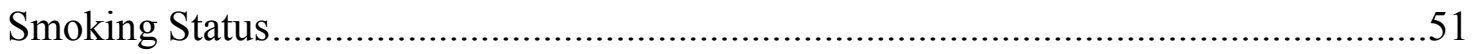

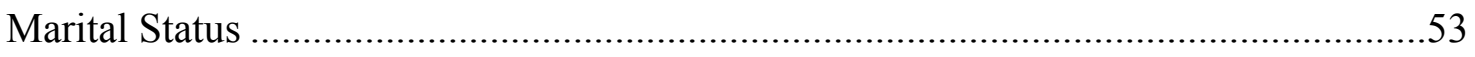

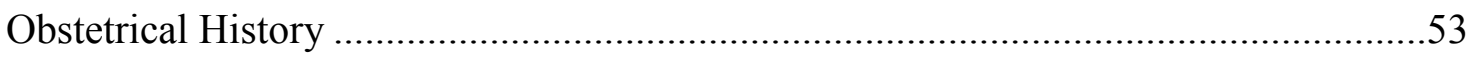

Observed Frequency of Abnormal Pap Results ...........................................................53

Relationship between Cytology and Histology According to Progesterone

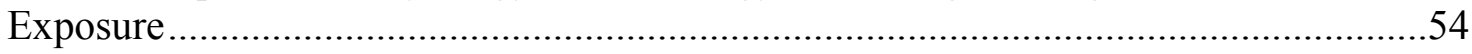

Difference in Relationship between Cytology and Histology According to Progesterone Exposure ................................................................................................55

Relationship between Cytology and Histology, by Length of Time Using either Depot Medroxyprogesterone Acetate or Progesterone IUD .......................................56

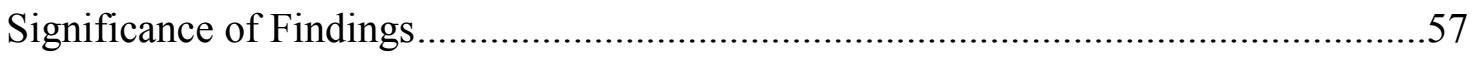

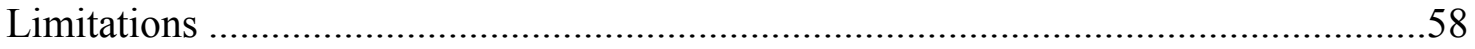

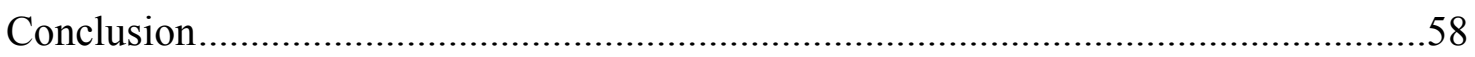

LIST OF REFERENCES ....................................................................................................61

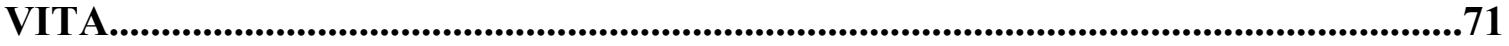




\section{LIST OF TABLES}

Table 3-1. Categorization of cytology and histology results into collapsed

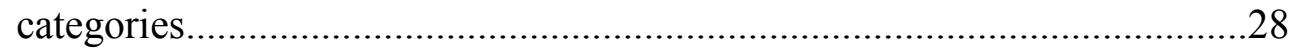

Table 3-2. Definition of agreement between cytology and histology ...........................29

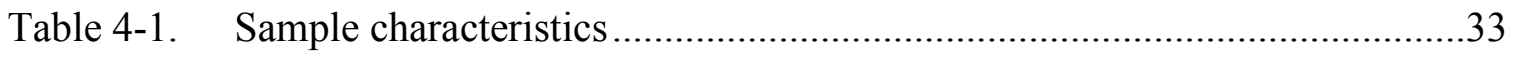

Table 4-2. Cytology result, cervical histology result, and endocervical curettage result by progesterone exposure $(\mathrm{n}=180) \ldots \ldots \ldots \ldots \ldots \ldots \ldots \ldots \ldots \ldots \ldots \ldots \ldots \ldots \ldots \ldots \ldots \ldots . . . .36$

Table 4-3. Crosstabulation of collapsed cytology and histology results for all cases $(\mathrm{n}=180)$

Table 4-4. Crosstabulation of collapsed cytology and histology results for no progesterone exposure $(n=72)$

Table 4-5. Crosstabulation of collapsed cytology and histology results for progesterone IUD $(\mathrm{n}=35)$

Table 4-6. Crosstabulation of collapsed and histology results for progesterone injection $(\mathrm{n}=73)$

Table 4-7. Crosstabulation of collapsed cytology and histology result for any progesterone exposure $(\mathrm{n}=108)$.

Table 4-8. Agreement between cytology and histology results by progesterone exposure

Table 4-9. Agree, false negative, or false positive results between cytology and histology by progesterone exposure.

Table 4-10. Tests of the cytology/histology relationship and progesterone exposure ....47

Table 4-11. Post hoc power analyses. 


\section{CHAPTER 1. INTRODUCTION}

\section{Overview}

Cervical neoplasia is the third most common gynecologic neoplasia affecting women worldwide. ${ }^{1}$ Death rates from cervical neoplasia have steadily dropped over the past few decades as the use of Papanicolau (Pap) testing to screen for cervical neoplasia has become the standard of care. ${ }^{2}$ The majority of cervical neoplasia deaths in the U.S. occur in women who have never been screened, or have not been screened in the five years prior to the abnormal Pap result. However, death from cervical neoplasia has been noted among women with a recent negative Pap result which occurs as a result of detection error in Pap interpretation. ${ }^{3}$

In the early 1990's, human papillomavirus (HPV) DNA was discovered in virtually all cervical neoplasia. This has led to numerous studies of the causal relationship between HPV and cervical dysplasia and neoplasia and has been widely investigated and validated. ${ }^{4-10} \mathrm{HPV}$ is a DNA virus that is sexually transmitted. There are approximately 30-40 urogenital subtypes of HPV, with types 16 and 18 being implicated as the cause of approximately $70 \%$ of all cervical neoplasia. ${ }^{11}$ The high risk subtypes are associated with the development of cervical dysplasia/neoplasia; whereas, the low risk subtypes are associated only with genital skin lesions.

Much has changed in the last 25 years in the knowledge of causative factors of cervical neoplasia. Screening for cervical neoplasia evolved with the arrival of HPV testing as an adjunct to the Pap test. However, Pap screening remains the standard of care for the detection of abnormal cervical cells in a woman who has cervical dysplasia or cervical neoplasia. Early detection and treatment of cervical neoplasia for many depends on accurate cytologic interpretation. The sensitivity of the Pap test has been shown to fall within a range of 50-75\%. ${ }^{12}$ A 1999 Agency for Health Care Policy Research review set Pap test sensitivity within a range of $51-66 \%$ for detection of all grades of cervical intraepithelial neoplasia (CIN) and slightly higher for high grade lesions (not exceeding $70-80 \%) .{ }^{13}$ Uyar et al (2003) noted cytologic screening to have a high sensitivity from $55 \%$ to nearly $100 \%$ for detecting squamous cell neoplasia. ${ }^{14}$

Cytologic screening relies on the subjective interpretation of the sample by a pathology professional. Theoretically, any factor which affects the cells contained in the sample may also affect the subsequent interpretation of the sample. Exogenous hormones affect cervical cellular characteristics. ${ }^{15-17}$ Exogenous hormones include all hormones to which a woman is exposed to in addition to what she produces endogenously. ${ }^{1,18}$ Exposure to exogenous hormones may occur in the course of a woman taking either contraception or hormone replacement therapy. Cellular effects related to exogenous progesterone exposure include crowding of cells, curling of cells, and the presence of navicular cells (glycogen filled squamous cells with thickened borders). ${ }^{16}$ These cellular alterations may lead to difficulty with cytologic interpretation, though little research has been conducted on the issue. ${ }^{15-17}$ Progesterone only contraceptive methods are used by as many as $19 \%$ of women in the United States. ${ }^{19,20}$ This means that these women may 
potentially be affected by any phenomenon which exists between progesterone exposure and variation in cytologic interpretation.

Findings to date regarding a definitive effect of progesterone on cytologic interpretation are conflicting. Some studies demonstrate a greater number of false negative, ${ }^{21}$ and some a greater number of false positive cervical changes. ${ }^{16}$ Further research is needed to determine the relationship between cytology and histology in women using progesterone contraception and whether that relationship differs from women not using progesterone contraception. Interpretation rates will be affected if there is a difference in the relationship between cytology and histology results in women using progesterone contraception. These changes in interpretation rates could have an affect on the rate of cervical dysplasia and neoplasia. This study included a control group of women using either non-hormonal contraception, or no contraception. This work contributes to the existing body of knowledge by comparing groups of women with abnormal cytology results who have either no, or varying types of progesterone exposure to women with no recent ( $>6$ months) progesterone exposure. No study to date has compared progesterone IUD users to progesterone injection users against a control group of women without recent progesterone exposure. This study focused on the relationship of cytology to histology in women using two different progesterone only contraception methods compared to a control group not exposed to progesterone. Addressing this question will inform us if progesterone and progesterone delivery method affects cervical cytologic interpretation and ultimately the diagnosis of cervical neoplasia.

\section{Problem Statement}

Cervical neoplasia screening and diagnosis begins with, and is dependent upon, the accurate interpretation of cytologic specimens. Women who have abnormal cytologic screening results undergo a colposcopy with possible cervical biopsy and/or endocervical curettage. This is the standard of care for follow up once a woman has an abnormal cytologic screening result. Colposcopy is an invasive procedure for which women experience a high level of anticipatory anxiety over the potential pain involved, outcomes, and lifelong implications. ${ }^{22-24}$

Any effect that progesterone may have on the accuracy of cytologic interpretation has far reaching effects on women whose cytologic samples may be erroneously interpreted. Women would undergo an unnecessary and costly colposcopic procedure should progesterone exposure lead to false positive results. Women who do not truly need colposcopy but who are referred for colposcopy based on abnormal cytology are at risk for physiologic and psychological morbidity. Women who undergo colposcopy experience negative mental health effects as far as two years after having received the abnormal cytologic screening result. ${ }^{25,26}$

The economic effect of women undergoing unnecessary colposcopy is also an important issue that cannot be underestimated. An estimated range of $10-30 \%$ of the 50 million cytologic annual screening tests done in the U.S. return with a result of atypical

squamous cells of undetermined significance (ASCUS). ${ }^{27,28}$ Considering that $1 \%$ of these 
ASCUS results require further colposcopic work up, between 25 million and 75 million dollars annually are used for women undergoing unnecessary colposcopy and/or biopsy. By identifying any association in women using progesterone only contraception and a variance rate in interpretation, the manner in which high risk HPV infected women should be counseled regarding contraceptive choice will be affected.

A false negative cytologic screening result (where pathologic markers in the cytologic sampling are misinterpreted as normal) could mean that women with advanced cervical pathology may go undetected and develop cervical neoplasia. Undetected high grade squamous epithelial lesions are at the greatest risk of evolving into cervical neoplasia over time. A consensus in the literature suggests that, left undetected, greater than $50 \%$ of women with low grade squamous epithelial lesions go on to progress to cervical intraepithelial neoplasia III (CIN III) within a period of 5 years. ${ }^{27}$ In summary, exogenous progesterone may lead to either false-positive or false-negative results on cytologic screening. Both results can have important psychological and physical consequences, including death due to delayed cancer diagnosis.

\section{Purpose}

The purpose of this exploratory study was to examine the accuracy of cervical cytologic findings in women who were using either one of two forms of progesterone only contraception, depot medroxyprogesterone acetate injection or the progesterone IUD, as compared to women who either used a non-hormonal form of contraception or no contraception. Accuracy, for the purposes of this study, was defined as the association between cytology interpretation and histology interpretation. A secondary purpose of the exploratory study was to investigate whether the length of time of progesterone exposure had an effect on the association between cytologic and histologic findings.

\section{Questions}

1. What are the characteristics (demographic, gynecologic, and smoking history) of four groups of women who have abnormal cytology test results?

1a. Those who use the progesterone IUD.

1b. Those who use depot medroxyprogesterone acetate.

1c. Those who use either no contraception or a non-hormonal contraceptive method.

1d. Those who use either the progesterone IUD or depot medroxyprogesterone acetate.

2. What is the relationship between cytology and histology in four groups of women with abnormal cytology results?

2a. Those who use the progesterone IUD.

2b. Those who use depot medroxyprogesterone acetate. 
2c. Those who use either no contraception, or a non-hormonal contraceptive method.

2d. Those who use either the progesterone IUD or depot medroxyprogesterone acetate.

3. Is there a difference in the relationship between cytology and histology in four groups of women with abnormal cytology results?

3a. Those who use the progesterone IUD.

3b. Those who use depot medroxyprogesterone acetate.

3c. Those who use either no contraception or a non-hormonal contraceptive method.

3d. Those who use either the progesterone IUD or depot medroxyprogesterone acetate.

4. Is there a difference in the relationship between cytology and histology, by length of time using depot medroxyprogesterone acetate or the progesterone IUD?

\section{Significance of the Study}

The knowledge that there may be an association between progesterone only contraceptive methods and altered interpretation of the cytologic screening test is important. Cytologic screening is crucial in detecting cervical dysplasia. Women infected with a high risk HPV type need to be informed of the risks associated with using progesterone only contraception and potential for inaccurate cytologic screening interpretation should an association exist cytopathology professionals interpreting the cytologic sampling would also need to be aware of the woman's use of a progesterone only product, and how that may affect the characteristics of the cervical cells in the sampling they are interpreting. In addition, improved screening techniques could be developed to better delineate cervical cells with non-pathologic cytologic changes as a result of progesterone, from those with cellular changes which are truly of consequence.

\section{Definitions of Terms}

Terms to be defined include Papanicolaou screening, combined oral contraception, colposcopy, progesterone intrauterine device, and depot medroxyprogesterone acetate. Terminology used to describe collapsed cytology and histology groups includes low grade and high grade, and is defined. Other terms include all terminology used to describe abnormal cervical cytology (atypical squamous cells of undetermined significance (ASCUS), atypical squamous cells of undetermined significance, cannot rule out high grade (ASC-H), low grade squamous intraepithelial lesion (LSIL), high grade squamous intraepithelial lesion (HSIL), squamous cell carcinoma, and atypical glandular cells (AGC). The terminology used to define abnormal histology includes: cervical intraepithelial neoplasia (CIN I, II, or III), squamous cell neoplasia in situ, invasive squamous cell carcinoma, adenocarcinoma in situ, and invasive adenocarcinoma. 
1. Papanicolaou screening, or Pap test, is the primary cytologic screening test currently available for cervical neoplasia. Exfoliated cervical cells are collected and prepared for microscopic evaluation by a pathology professional. ${ }^{29}$ The terminology of cytologic screening refers to screening achieved via collection of the Pap test.

2. Combined oral contraception methods (COCs) are those which contain both the hormonal components of estrogen and progesterone. The hormones are released from the oral preparation at either a constant rate (monophasic preparation), or at varying rates (biphasic/triphasic preparations) through the entire monthly cycle. ${ }^{30}$

3. Colposcopy is the procedure for examining the cervix after an abnormal cytologic screening test result. This involves the application of a dilute solution of acetic acid to the cervix, after which a colposcope (a high power microscope) is utilized to visualize cervical lesions. A histologic sampling, or biopsy, may or may not be collected at the time of colposcopy, based on the clinical judgment of the colposcopist.

4. Progesterone intrauterine device is an intrauterine system of contraception that releases the progestin levonorgestrel on a steady basis directly into the uterine cavity.

5. Depot medroxyprogesterone acetate is an injectable form of progesterone (150 milligrams per dose) that is long acting, requiring injections every three months.

6. Low grade cytology includes the following cytology classifications: ASCUS no HPV result, ASCUS HPV positive, ASCUS HPV negative, and LSIL.

7. High grade cytology includes the following cytology classifications: HSIL, AGC, ASCUS-H, and LSIL-H.

8. Low grade histology includes the following histology classifications: Cervicitis, CIN I.

9. High grade histology includes the following histology results: CIN II, CIN III, CIS, invasive neoplasia, adenocarcinoma.

All of the following cytologic interpretation categories are assigned through the Bethesda system of classification which is the systematic method of cytologic test abnormality classification currently in use in the U.S. ${ }^{31}$

1. Atypical squamous cells of undetermined significance (ASCUS) is a designation assigned by pathologists to cytologic screening samples when there are cervical cells with abnormal features that result in an unclear impression as to whether they are inconsequential, or problematic in nature. ${ }^{31}$ Atypical squamous cells of undetermined significance cannot rule out high grade (ASC-H) is a cytologic designation assigned to cytology samples where immature squamous cells with properties similar to high-grade dysplasia are noted. ${ }^{31}$ The defining pathologic sign for dysplasia is abnormality of the cell nucleus. 
2. Low grade squamous intraepithelial lesion (LSIL) is the designation assigned to cytologic samples where the cell nucleus is at least three times larger than that of normal cells. There are also other abnormal morphologic criteria present in cytology samples designated as LSIL, such as irregular nuclear shaping, wrinkling of the cell membrane, and multiple nuclei. ${ }^{31}$

3. High grade squamous intraepithelial lesions (HSIL) have some abnormal cellular features that may be similar to samples that are LSIL, with the addition of a greater nucleus to cytoplasmic ratio. ${ }^{31}$

4. Atypical glandular cells (AGC) is the designation assigned when the glandular cells in the cytologic sample contain cellular abnormalities that cannot be definitively diagnosed as either benign, premalignant, or malignant. ${ }^{31}$

5. The cervical intraepithelial system (CIN) is the grading system reserved for gradation of histologic samples collected at colposcopic exam. The level of $\mathrm{CIN}$ is assigned according to the degree of abnormal cellular proliferation present. CIN I is assigned to histologic samples where a mild degree of dysplasia, or abnormality, is noted. CIN II histologic samples are consistent with a moderate degree of dysplasia. CIN III histologic samples are designated as such because they denote characteristics of severe dysplasia and/or neoplasia in situ. ${ }^{31}$

6. Squamous cell neoplasias the form of neoplasia which affects squamous cells. Here, the term refers specifically to the squamous cells of the cervix. Whether it is contained within the cell (in situ) or has spread beyond the cell borders (invasive) is designated within the histology report.

7. Adenocarcinoma is designated to histology sampling that indicates a malignancy originating in the glandular epithelium of the cervix. ${ }^{29}$ Whether it is contained within the cell (in situ) or has spread beyond the cell borders (invasive) is also designated within the histology report.

\section{Assumptions}

This study had multiple assumptions:

1. The evidence describing the relationship between exogenous progesterone and subsequent effect on cervical cells was salient and would support why a difference in interpretation accuracy may exist.

2. The mode of data measurement and subsequent analysis adequately captured what was known about the key concepts.

3. Any evidence gleaned as a result of the study method and data analysis would be adequate to either support or deny any relationship between progesterone use and accuracy of cytologic interpretation. 
4. The delivery system and the dosage of the exogenous progesterone could have had specific influence on hormonal cellular effects, underscoring why two methods of progesterone delivery were included in the study.

\section{Limitations}

A primary limitation of this study was threat to internal validity. There was an inability to control for either the same practitioners collecting the samples, or the same pathology professionals interpreting the samples. The study undertook the examination of existing cytologic and histologic reports contained within the subject's records. Another limitation of the study involved the use of an electronic database used for the data. Data, particularly demographic data, may have been missing from patient records. In addition, patient records rely on the information first being correctly entered by patient care providers. However, the advantage of using this large database was for this particular study was the large number and heterogeneity of the subjects.

\section{Conceptual Framework}

The framework underpinning this study included the key concepts of cervical cells that exhibited changes that occurred as either the result of progesterone exposure, HPV exposure, or both. Other key concepts included exogenous progesterone, either in the form of depot medroxyprogesterone acetate or the progesterone IUD, cytologic interpretation, and histologic interpretation. The relationship among the key concepts and the cytologic and histologic interpretation of the cervical cells was the focus of this study. The state of the science includes the most prominent key variable of cervical cytology interpretation. The development of squamous intraepithelial abnormalities follows the course of the host first being infected with a high risk type of HPV after which the basal cells of the stratified epithelium are affected first. ${ }^{32}$ Lower levels of dysplasia demonstrate squamous cells wherein HPV produced proteins have caused cellular death, exfoliation and disintegration. Actual integration into the host cell's genomic structure is noted with higher level dysplasia. This integration leads to further production of neoplastic proteins which then promote change of immature basal and parabasal cells. The dysplastic basal and parabasal cells have the opportunity to spread and invade surrounding endocervical glands though the basement membrane maintains integrity. ${ }^{31}$ Invasion of the neoplasia into surrounding tissue will occur once the basement membrane is compromised.

Exogenous progesterone changes cervical cellular characteristics. ${ }^{7,17}$ Cellular characteristics which have been associated with the effect of progesterone exposure include curling or crowding of squamous cells, destruction of cells, and unusual morphology to cells (navicular or classically called "boat shaped"). ${ }^{16}$ This cellular phenomenon caused by progesterone has the potential to affect the cytological interpretation of the cells. Progesterone is thought to promote atrophy of the epithelial cells as well as to decrease the cellular maturation pattern. ${ }^{5,33}$ The resultant atrophy of the 
squamous epithelial cells and the change in expected maturational progression can mimic changes which are specific to cellular dysplasia, without actually being dysplastic.

The cytologic interpretation of the cervical cell specimen dictates whether a woman is referred for colposcopic examination, and this means that the effect of exogenous progesterone as a potential variant in cytologic accuracy is important. Very little research exists on the issue of cervical cell exogenous progesterone exposure and the relationship to cytologic interpretation. Cytologic interpretation of cervical squamous epithelium via the Pap test has a sensitivity of $80 \%$ (range of $51-83 \%),{ }^{31}(50-75 \%),{ }^{12}$ and a specificity of $95 \%$ for detection of abnormal cervical cytology. Cytology is part of the current standard for screening for cervical dysplasia. ${ }^{34}$ The basis for cytologic screening is the premise that abnormal cervical squamous epithelium cells and neoplastic endometrial cells are shed into the secretions of the cervix and vagina. These secretions are then transferred to a medium, whether in liquid or fixed onto glass slide, and then examined by a pathologist. ${ }^{35}$ One of the errors that can occur with cytologic screening accuracy is failure of correct cellular interpretation. ${ }^{14}$ Interpretation of the cervical cytology precedes recommendation for colposcopic examination and histologic interpretation of cervical tissue collected at the time of colposcopy.

Histologic interpretation of the tissue submitted at colposcopy is the diagnostic measure used to determine the underlying cause of the abnormal cytologic screening. The colposcopist identifies abnormal visual features and decides whether biopsy is indicated. The colposcopist's main goal is that of not letting cervical neoplasia go undetected. ${ }^{36}$ Stafl and Mattingly (1973) documented the diagnostic accuracy of colposcopically directed biopsies as equal to that of tissue obtained by cold knife cone biopsy. ${ }^{37}$ The cervical biopsy done under colposcopy has now become the standard of care for the diagnosis of cervical dysplasia.

The concept of relationship between histology and cytology is important in that the cytology results direct subsequent histological examination. The ASCUS/LSIL Triage study (or "ALTS," as it is referred to) of 1995-2001 set the standard for much of what is known about the relationship between abnormal cytology and subsequent histology. ${ }^{13}$ Treatment of cervical dysplasia and neoplasia is determined by the histology result, thus clinicians and researchers must understand the relationship between cytology and histology. Further, factors that may affect that relationship need to be well understood. 


\section{CHAPTER 2. REVIEW OF LITERATURE}

Five major areas of the literature will be reviewed. The first section reviews the physiologic process of both normal and abnormal squamous cell metaplasia. The literature on HPV is then reviewed, as HPV persistence is the main known etiologic agent for development of cervical dysplasia and cervical neoplasia. The second section is a discussion of the pathologic characteristics of each of the types of abnormal cytologic classifications. The section also reviews cytologic classifications, according to the Bethesda system ${ }^{31}$ of classification currently in use. Comprehension of the classification system is critical to the understanding of cytologic abnormalities are classified. The third section addresses the literature on cervical neoplasia and combined hormonal contraceptive use (contraception that contains both of the hormones estrogen and progesterone). The rationale for reviewing the literature encompassing the use of both estrogen and progesterone is that the majority of literature on the effect of exogenous hormones lies in this arena. The fourth section is an overview of the literature on cervical neoplasia and progesterone use and lays the foundation for the final section which focuses solely on the existing literature dealing with the progesterone effect on cervical cells. An understanding of the progesterone induced changes which occur in cervical cells is critical to comprehension of how cellular changes can affect cytologic interpretation.

\section{Overview of Squamous Metaplasia and Human Papilloma Virus as Etiology of Cervical Neoplasia}

Cervical neoplasia is the third most common gynecologic neoplasia affecting women worldwide. ${ }^{1}$ Invasive squamous cell neoplasia of the cervix is preceded by identifiable cellular precursors. ${ }^{38}$ The human cervix is composed of stratified squamous cells as well as columnar cells, with the major portion of the cervical portio lined with the stratified squamous cells. Metaplasia constantly occurs as the columnar cells become stratified squamous cells, and glandular cells of one type evolve into different types of glandular cells. Cervical metaplasia is not completely understood but is thought to be initiated by the move of the original squamocolumnar junction (SCJ) onto the cervical portio and the exposure of columnar cells to the acidic vaginal environment. The SCJ is the area on the cervical surface where the columnar cells of the internal os of the cervix meet the stratified squamous cells of the ectocervix, and the former SCJ moves outward on the surface of the cervix as new cells continually form. The area between the "old" and the "new" SCJs is called the transformation zone and is where these two types of cells meet. Cervical metaplasia occurs within the transformation zone and is the most likely site for dysplasia to also occur. ${ }^{31}$

\section{Process of squamous metaplasia}

The process of squamous metaplasia refers to the naturally occurring and benign evolution of cells of the squamous epithelium. There are multiple layers to the squamous 
epithelium and each layer has specific cell and protein types. Basal, or basement membrane cells, form the deepest layer. The next layer up is the stratum and contains the parabasal cells which have a differentiation function. An important difference between the basal and parabasal cells is that the parabasal cells have proliferating nuclear antigen (PCNA) as well as protein RB (pRB). Basal cells do not contain PCNA, which keeps them in a quiescent state as opposed to one of active division. ${ }^{31}$ Reserve cell hyperplasia, is a sole layering of subcolumnar reserve cells and also occurs along with these cellular processes. In summary, this ongoing simultaneous activity of varied types of cells, in various stages and speeds of evolution, at various levels of the epithelium, is a function of normal squamous epithelium. ${ }^{39}$ There is concomitant deterioration of the existing columnar cells in the process of reserve cell propagation. The last step in the metaplastic process is that of the endocervical glands undergoing metaplasia and joining the superficial squamous cells. ${ }^{31}$ The SCJ has great potential for neoplastic cells to develop as the immature metaplastic squamous cells become mature metaplastic squamous cells, replacing columnar cells, and later becoming stratified squamous cells. ${ }^{40}$ Both the rate and the degree of metaplasia have been singled out as predictors for dysplasia development. ${ }^{41}$ Other factors which aid in the process of squamous metaplasia include: changes in hormonal balance (such as with menarche, pregnancy, and menopause); chronic inflammation; and $\mathrm{pH}$ changes. ${ }^{31}$

\section{Development of squamous intraepithelial abnormality}

The development of squamous intraepithelial abnormalities occurs with the host being infected with a high-risk type of HPV, after which the basal cells of the stratified epithelium are primarily affected first. ${ }^{32}$ It is not merely the presence of HPV infection that is the impetus for cervical dysplasia, but the persistence of the HPV infection. Cervical dysplasia is known to be multifactorial, with risk factors increasing the likelihood of development of dysplasia in a woman infected with HPV. ${ }^{4}$ Cervical intraepithelial neoplasia I (CIN I) lesions demonstrate squamous cells wherein HPV produced proteins have caused cellular death, exfoliation, and disintegration. With CIN II and CIN III lesions, actual integration into the host cell's genomic structure is noted, which instigates further production of neoplastic proteins which then promote change of immature basal and parabasal cells. The dysplastic basal and parabasal cells have opportunity to spread and invade surrounding endocervical glands, though the basement membrane maintains integrity. ${ }^{31}$

\section{Development of glandular abnormalities}

Glandular lesions usually arise in the transformation zone, though they may occur anywhere in the endocervical canal. The reactive cellular changes that occur with glandular abnormalities are similar to the changes that occur in squamous metaplastic cells. Glandular epithelium can retain its original state throughout the cell's life; it can convert to glandular neoplasia, convert to normal squamous epithelium, or become a squamous neoplasia, via the process of atypical metaplasia. The evolution of the various 
types of glandular cells can occur simultaneously; therefore, it is not unusual to see mixed disease wherein adenocarcinoma coexists adjacent to a squamous cell lesion. ${ }^{42}$

The pathophysiology of normal glandular cell conversion to neoplasia is not well understood. Abnormal glandular cell development is likely a multifactorial event which occurs with the presence of particular persistent HPV types in combination with vaginal $\mathrm{pH}$ changes, hormonal changes, or cellular trauma. Squamous cell metaplasia, whether normal or abnormal, is not the stimulus for glandular disease. ${ }^{31}$ There is disagreement as to whether glandular abnormality is connected to reserve cell hyperplasia, which has also been implicated in the development of squamous cell neoplasia. Cytokeratins 6 and 16 appear to be more prevalent in squamous metaplastic cells that become dysplastic, while cytokeratins $4,10,13$, and 14 are more commonly expressed in squamous cells that do not become dysplastic. ${ }^{31}$ The hypothesis of atypical glandular cell formation is that reserve cells, beneath the columnar epithelium become hyperplastic through a process stimulated by both the presence and persistence of high risk HPV, in particular types 16 and $18 .^{43}$ Pathologists note atypical glandular cells in either stratified or pseudostratified formation which may be single or multilayered upon examination of cytologic sampling. ${ }^{31}$ Glandular lesions generally exhibit the following characteristics under cytopathologic examination: 1) specific clustering of glandular epithelium with hyperchromatic nuclei, 2) fragmented nuclei, and 3) an elevated mitotic index. ${ }^{38}$

Cytologic screening results of atypical glandular cells (AGC) are fairly uncommon $(0.5-1 \%)$ and between $17 \%$ and $59 \%$ of women with this result have oncogenic lesions present. ${ }^{44}$ In contrast, ASCUS cytologic screening results are the most common cytologic screening abnormality reported, yet only $5-10 \%$ of women with an ASCUS result actually have a high grade lesion (CIN II or greater) present. Adenocarcinoma, either invasive or in situ, will be found in approx. 5-10\% of women with AGC cytology screening results. A larger proportion of cervical neoplasias with an AGC screening result will be found to have adenocarcinoma/adenosquamous findings on the histological exam. ${ }^{45}$

\section{HPV as etiologic agent in neoplastic development}

HPV plays a central role in the development of cervical neoplasia. At least 50\% of sexually active persons will be infected with at least one type of urogenital HPV during their lifetime, and some estimates extend that to as high as $80 \%$. ${ }^{46}$ The presence of persistent HPV is a necessary but not sufficient component for the development of cervical dysplasia and neoplasia. Only a very small proportion of women infected with HPV develop cervical neoplasia. This fuels the assumption that cervical neoplasia is a multifactorial phenomenon. Numerous studies have consistently demonstrated HPV DNA in the cervical specimens of women with cervical neoplasia $90-100 \%$ of the time, compared to a prevalence of $5-20 \%$ in studies with equal controls. ${ }^{47}$

There are over 100 various types of HPV, and as many as 40 affect the human urogenital tract. Types 16 and 18 are implicated as the cause of approximately $70 \%$ of all cervical neoplasias. ${ }^{11}$ Approximately 13 strains are labeled as high risk types because 
they increase a woman's risk of cervical neoplasia. Low risk types, particularly 6 and 11, are the major cause of visible HPV lesions of the anogenital tract, but do not increase a woman's risk for cervical neoplasia. The largest demographic group of newly infected females are young women below the age of 25 at coitarche. ${ }^{48}$ Infection in young women tends to be of a transient nature, with persistent infections developing in approximately 5$10 \%$ of those infected. The persistence of the HPV infection is thought to be the impetus for pre-cancerous and cancerous lesions more so than just the presence of HPV.

There is question in the literature as to whether HPV viral load has a positive association with any of the grades of cervical intraepithelial neoplasia. Huang et al. (2008) found HPV DNA load, as detected by hybrid capture, was not consistently associated with cervical lesion severity. ${ }^{51}$ In contrast, Bosch et al. (1993) noted higher viral HPV loads were associated with lesions of greater severity. Ho and colleagues, in their work looking at messenger RNA levels and relationship to severity of cervical neoplasia, suggested that the transcriptional activity of high risk HPV types is varied. ${ }^{52}$ Specific high risk HPV types $(16,18,52$, and 58) are the catalyst for host cell chromosomal instability to a variable extent, depending on the amount of high risk HPV E6 messenger RNA. ${ }^{53}$ Thus, Ho and colleagues concluded that quantifying levels of HPV E6 mRNA may in fact be a superior method of measuring dysplastic severity. ${ }^{52}$

The genomes of high risk HPV are thought to be confined to the basal cells of the epithelium following infection. ${ }^{54,55}$ This is where the HPV oncogenes gain access into the S-phase of cellular mitosis and replication of the virus is activated. ${ }^{56}$ Of note, genetic expression during this mitotic phase is of no pathologic consequence as the changes are occurring among cells that are shed during the continuous cycling of the squamous epithelium. ${ }^{57}$ The persistence of HPV infection is required for the eventual progression to neoplasia. High risk types of HPV maintain persistence via their involvement in the mitotic phase as described. When this occurs, the normal order of cellular evolution and maturation is disrupted throughout all of the layers and evolves to abnormal cell production. ${ }^{58}$ The degree of HPV expression within the cervical cells is a crucial determinant in the severity of the cervical dysplasia. For instance, basal cell oncogenic expression is noted completely through all of the cellular layers in CIN II and higher lesions. Conversely, there is an inhibition of basal oncogenic expression throughout all cellular layers in CIN I lesions. ${ }^{59-61}$

\section{Cytopathologic and Histopathologic Characteristics of Cellular Lesions and Classification of Abnormal Pap Results}

\section{Review of abnormal cytology}

Microscopic examination of the cytologic sample collected from the cervix via the cytologic screening test involves detection of certain cellular characteristics including aberrations of the nuclear chromatin, size and shape of the nucleus in relation to the cytoplasm, and keratinization. ${ }^{27}$ The critical feature in identifying dysplasia is altered nuclei formation. Dysplastic cells have an enlarged nucleus with an irregular nuclear 
membrane and pronounced nuclear chromatin. LSIL lesions exhibit these changes in the mature epithelial cells. In contrast, HSIL lesions exhibit these changes in the immature cells (basal and parabasal). ${ }^{31}$

Cytologic screening characteristics of LSIL include modification of the epithelial thickness, atypical nuclei in upper layers of the epithelium, no atypia in the parabasal and basal layers, and cellular polarity maintenance. Other characteristics which may be present include binucleated cells with larger than normal hyperchromatic nuclei, and irregular halos of cytoplasm. ${ }^{38}$ Differentiating LSIL from HSIL includes the identification of cells in the lower epithelial layers which have a high nucleus to cytoplasm ratio with chromatin that is coarse in appearance. Other cellular characteristics which distinguish LSIL lesions from HSIL lesions include fewer mitoses among the cells in LSIL lesions, and those abnormal cells present limited to parabasal and basal cellular layers. Cells in LSIL lesions demonstrate cell polarity perpetuation, atypical nuclei absent from lower layers, and lack of mitotic figures. ${ }^{38}$

\section{Atypical squamous cell classification}

Atypical squamous cells may develop in response to stimuli in the vagina (intercourse, infection, tampon use) that are completely unrelated to either HPV infection or existing dysplasia. Cellular changes that occur in response to HPV infection may be classic (larger than normal, irregularly shaped nuclei within ballooning cytoplasm, or with a perinuclear halo). HPV effect may also produce less distinctive cellular effects. ${ }^{31}$ ASCUS is the likely cytologic screening interpretation when cellular changes are noted, which are not certain markers for HPV infection, or when the number of abnormal cells is very few. The risk of having a dysplasia is very low for women who test out with ASCUS, HPV negative. HPV positive women with ASCUS results are 12.5-23 times more likely to actually have CIN II, III than women who are not HPV positive. ${ }^{62}$ ASCUS is the most common cytologic result. Approximately 2-3 million women annually have an ASCUS cytologic screening result. ${ }^{63,64}$

\section{Low grade squamous intraepithelial lesion (LSIL) classification}

A cytologic screening result of LSIL would indicate cells that have either a polymorphonucleocytenucleus or nuclear size that is three times that of normal and abnormal in shape, with irregular membrane consistency. The nucleus of these cells is confined to approximately one third of the cellular area. The cellular abnormalities are limited to the most superficial of cells, and there is a definitive border between the cellular cytoplasm and the perinuclear clearing within the cell. ${ }^{64,65}$ Incidence rates for LSIL cytologic screening results have been quoted from $1.6 \%$ to $7.7 \%{ }^{66}$ Low risk lesions have a very high rate of regression to normality, averaging $57 \%$, with a persistence of $32 \%$, and a progression rate to CIN III of $11 \%$. Total risk of progression to invasive neoplasia is only $1 \%{ }^{67,68}$ 


\section{High grade squamous intraepithelial lesion (HSIL) classification}

Cytologic screening results of HSIL have some common nuclear characteristics seen in LSIL cytology specimens and some distinct differences. The nuclei of HSIL cells occupy much more cellular area than the LSIL cell nuclei. Approximately half of the total cellular area in HSIL specimens is occupied by nuclei, as compared to one third for the LSIL specimens. The nucleus to cytoplasm ratio, therefore, is greater in the HSIL cell than it is in the LSIL cell. Cells of an HSIL sample are also geometrically arranged side by side in single fashion, or in groups. ${ }^{65}$ HSIL has an incidence of $0.45 \% .{ }^{66}$ Lesions that result in an HSIL cytologic screening result are generally of CIN II or III or greater in severity. Regression of CIN II lesions has been calculated at $40 \%$, persistence at $40 \%$, progression to CIN III 15\% and progression to invasive neoplasia 5\%. CIN III lesions have a regression rate of $33 \%$, persistence of $55 \%$, and rate of progression to invasive neoplasia of greater than $12 \% .{ }^{69}$

\section{Invasive squamous cell neoplasia classification}

There must be basement cellular membrane and encroachment into the stroma lying beneath the basement membrane to classify a cytologic sample as invasive squamous cell carcinoma. There is visible evidence of cellular degradation within the sample, as well as inflammation and bleeding. ${ }^{70}$ Abnormal cellular shape is also characteristic of this cytologic result, with enlarged nuclei, which also exhibit coarse chromatin. ${ }^{65}$

\section{Atypical glandular cell classification}

Cellular characteristics of atypical glandular cells include indiscriminate cell borders and cellular spacing, enlarged nuclei, varying in shape and size with coarse chromatin. There is also a higher nuclear to cytoplasm ratio. ${ }^{71}$

\section{ASC-H and LSIL-H classification}

Both ASC-H and LSIL-H have the H designation added on to denote that the sampling exhibits characteristics of the original cytologic category named, with the additional caveat that there are cellular characteristics which are also high grade in nature. However, there are insufficient cellular characteristics present to designate the specimen as HSIL. ASC-H and LSIL-H both present a greater risk for cervical neoplasia development than either ASCUS or LSIL, but less risk than a HSIL cytologic screening result. ${ }^{31}$ ASC-H has an incidence of only $0.27 \%-0.6 \% .{ }^{72}$ 


\section{Description of cervical intraepithelial lesions}

A woman undergoes colposcopic examination following an abnormal cytologic screening test. At the time of colposcopy, a biopsy may or may not be indicated, according to the visual findings of the colposcopist. Koilocytes (cells which are the end product of degraded mature squamous cells and are permeated with HPV particles) are identified in CIN I lesions. The koilocytes are confined to the anterior layers of the squamous surface and have the enlarged nuclei, prominent chromatin and characteristically irregular or "wrinkled" appearing nuclear membrane - all of which are characteristics noted in those cytologic results of LSIL. Cells may also be multinucleated, and the cytoplasm immediately adjacent to the nuclei has a clear appearance due to the agglomeration of the cytoplasm towards the edge of the cells which casts a halo appearance around the nuclei. ${ }^{68,73}$

Histologically, CIN II lesions are distinguished from CIN I lesions by the extent of propagation of abnormality extending to the parabasal and basal cell layers. ${ }^{68,74,75}$ Irregularly shaped, enlarged nuclei are also noted, with darkened and grainy chromatin filling the nuclei. There is variation among nuclear size, and some degree of nuclear overlay may be present. ${ }^{31}$ Invasive neoplasia presents with the interrupted basement membrane with the phenomenon of "nests" of malignant cells evidenced throughout the stromal cell layer. Prominent, oversized nuclei and course chromatin with accompanying inflammation is also characteristic. ${ }^{65}$

\section{Cervical Neoplasia and Combined Hormonal Contraceptive Use}

The cellular effect of exogenous combined progesterone and estrogen hormonal contraception (COC) has been studied with confounding results. ${ }^{76-78}$ The mechanism whereby exogenous combined contraceptive use may increase a woman's risk for cervical neoplasia is thought to be via binding of the steroid contraception to particular DNA sequences in the transcriptional areas of the HPV DNA. ${ }^{1}$ The elevated levels of endogenous progesterone and estrogen in women taking COCs may increase risk for proliferation of abnormal cells via indirect affect on the HPV infected epithelial cells. ${ }^{79}$ The transformation zone of the cervix has high affinity for sex hormone regulation, and in the presence of HPV and estrogen has been shown to be particularly sensitive to squamous lesion development. ${ }^{80}$ Sex hormones also have been noted to induce squamous metaplasia, which plays a role in cervical neoplasia development when HPV is present in the tissue. ${ }^{81}$

Moodley (2004) described the findings from eight studies conducted by the International Agency for Research on Cancer as well as a review on cervical neoplasia and the use of hormonal contraceptives. ${ }^{1}$ The author delineated four reasons for the conflicting and uncertain results on this issue. First, cervical neoplasia has an extremely long latent period which makes studying any associating factors extremely difficult. Second, over the course of their reproductive years, women are prescribed and use a variety of hormonal preparations. ${ }^{82}$ Thus, any association between a particular woman's cervical dysplasia or neoplasia and a type of hormonal contraception exposure may be 
confounded by the use of several different preparations during the latent period between HPV infection and neoplasia development. Third, little research on the use of COCs has been conducted in women over the age of 35 . Thus, knowledge is limited about the aging process and immune system function and the ability to avoid developing cervical dysplasia and neoplasia. Fourth, the author points to the wide variation in design methods and difference in data obtained in available studies. ${ }^{1}$

A study by the World Health Organization's International Agency for Research on Cancer (IARC) ${ }^{83}$ was included in the Moodley review and noted a fourfold increased risk of cervical neoplasia among women with persistent HPV infection and who had prolonged use of COCs. The IARC multicentric case control study reviewed eight studies of sexually active women from seven countries and effects were estimated as odds ratios with logistic regression models. The IARC group concluded that women taking COCs for 5-9 years were approximately three times more likely to develop cervical neoplasia as compared to non-COC users. Women using COCs for greater than ten years had a fourfold greater risk, as compared to non-COC users. ${ }^{1}$ Women who had used oral contraceptives for less than five years did not demonstrate an increased risk of cervical neoplasia compared to women who had never used COCs (odds ratio 0.73 ; 95\% CI 0.52 1.03). The odds ratio for use of COCs was 2.82 (95\% CI 1.46-5.42) for 5-9 years, and 4.03 (2.09-8.02) for COC use of 10 or more years. The odds did not vary by time from either first or last use of COCs ${ }^{83}$ The studies from which the pooled data were obtained were conducted in countries outside the U.S. including Thailand, the Philippines, Morocco, Brazil, Peru, Paraguay, Colombia, and Spain. The prevalence rates of the various types of high risk HPV differ from country to country, ${ }^{84}$ and this may account for some of the variation in results between those studies conducted in and outside of the U.S.

Conflicting findings were noted in reviews by Green et al. $(2003)^{85}$ and Smith et al.(2003). ${ }^{86}$ Smith et al. reviewed 28 studies to include 12,531 sexually active women with cervical neoplasia. ${ }^{86}$ The relative risks of cervical neoplasia increased in women who had used COCs compared with women who had never used COCs. Relative risk was calculated by the amount of years COC's were used. For a usage period of less than five years, five to nine years, and 10 or more years, respectively, the summary relative risks were 1.1 (95\% CI 1.1-1.2), 1.6 (1.4-1.7), and 2.2 (1.9-2.4) for all women; and $0.9(0.7-$ 1.2), 1.3 (1.0-1.9), and 2.5 (1.6-3.9) for HPV positive women. The results were similar for the type and degree of neoplasia (whether in situ, invasive squamous cell or adenocarcinoma). The authors concluded that the limited available data suggested that the risk of cervical neoplasia may decrease after cessation of use of combined oral contraceptives. Limitations noted by the authors include the variation in study designs, method of analysis, and methods for measuring HPV.

Green et al. (2003) reviewed 19 studies with data on HPV status and COC use, with a total of 20,509 subjects, to determine whether there was an association between the use of COC and HPV infection. ${ }^{85}$ The authors found no association between the use of COCs and the detection of HPV. Specifically, there was no association between duration of COC use and HPV positive status. A disparity noted among the studies was 
that all studies measured HPV positive status but no distinction was made between recent and persistent infection. The persistence of HPV infection has been well established as a necessary component for the development of neoplasia. ${ }^{7}$ A point of difference between the studies in the Green, et al (2003) ${ }^{85}$ review and those in the Smith, et al. ${ }^{86}$ review was that there were varying numbers of women with normal cytology included. Some of the studies included women with normal cytology while others included women with a mixture of normal and abnormal cytology. This heterogeneity in subjects could explain the difference in findings between studies. Green et al $(2003)^{85}$ also noted that there was no consistency between studies in relationship between HPV positivity and duration of COC use. Individual studies demonstrated increased, decreased or unchanged risk of HPV positivity by length of exposure to COC use. Some of the studies did not report length of progesterone exposure. Calculation of summary relative risks could not be done due to the lack of information on use duration as well as variability between study results.

A cohort study of more than 12,000 Argentinean and Brazilian women reported that length of use of hormonal contraception was not significantly related to an increased risk of high grade CIN. ${ }^{76}$ The variables that were noted to be associated with an increased risk of developing CIN (HR; 95\% CI) were LSIL cytology at baseline (1.99; 1.42 -2.80) and high risk HPV infection $(4.17 ; 1.74$ - 9.96). Factors found to be unrelated to development of CIN were: 1) baseline HSIL cytology; 2) young age at coitarche; 3 ) age over 35 years; 4) ever having been pregnant; 5) number of births; 6) current smoking status; and 7) being single. This study cohort used various methods of hormonal contraception, including COCs, progesterone injection, patch, implant, vaginal ring, or progesterone IUD, as compared to the studies reviewed by Smith et al. (2003) ${ }^{86}$ and Green et al. (2003) ${ }^{85}$ where the subjects used only COCs. The mode of delivery of contraception (transdermal, versus oral versus local), and formulation (combined versus progesterone) could affect outcomes. The authors appropriately noted that making assumptions about hormonal contraception use and HPV is extremely complicated because infection with HPV is closely associated with sexual behavior patterns, which is in turn closely related to the choice of contraception a woman makes. Longatto-Filho et al. (2011) note that those studies in which a causal relationship is suggested should control for sexual behavior as well as high risk HPV infection. ${ }^{76}$

Multiple reasons have been cited for the difference in findings regarding COC use and cervical neoplasia risk. These reasons include variable and poor research design, use of homogenous populations, the implication that women who use COCs have characteristically different sexual patterns, as well as external factors which independently increase the risk for cervical neoplasia. ${ }^{1,76}$ The argument has also been made that women who take COCs are more frequently screened for cervical neoplasia because they need to present periodically to their providers for a contraceptive prescription. $^{87}$

Two additional factors make it extremely challenging to study this issue. Women change contraceptive methods periodically throughout their reproductive years to prevent pregnancy, prevent sexually transmitted infections, or alter their menstrual cycle. ${ }^{88}$ This phenomenon makes it difficult to follow a cohort who use a singular method of 
contraception for an extended period of years. Second, a study group with exactly the same internal and external risk factors for cervical neoplasia is difficult to obtain. Controlling for all of the factors that could confound results would be optimal, but not practical. $^{84,87,89}$

\section{Cervical Neoplasia and Progesterone Use}

Progesterone alone has been implicated as a cofactor in the development of cervical neoplasia. Prolonged progesterone exposure was noted to enhance HPV colonization by way of increasing the HPV 16 E6/E7 oncogenic transcription. ${ }^{81} \mathrm{~A}$ corresponding greater presence of HPV DNA has been noted among women with higher serum levels of progesterone. ${ }^{90}$ Progesterone thins the cervical and vaginal epithelium, which may lead to erosion and a secondary inflammation of the cervical tissue. ${ }^{91}$

A WHO study did not demonstrate an increased risk of invasive neoplasia for women using depot medroxyprogesterone acetate for extended periods of time. ${ }^{92}$ The use of depot medroxyprogesterone acetate was inversely associated with the incidence of CIN II-III or greater (OR adj, 0.4; 95\% CI, 0.2-1.1) and CIN1 (OR adj, 0.1; 95\% CI, 0.01-0.6) among HPV positive women. Depot medroxyprogesterone acetate use was associated with high risk HPV (OR adj, 4.7; 95\% CI, 1.4-15.8) among women who were histologically negative. The authors did conclude that longer-term depot medroxyprogesterone acetate use may weaken the colposcopic and histologic features of CIN because women using the injection were more likely to have cervical oncogenic HPV without evidence of CIN. The subjects in the study self-reported their hormonal contraception use. The authors did not have documented information on whether the depot medroxyprogesterone acetate injections or COC use was continuous during the time period in which women reported having used the method. The subjects in this study who used COCs were using one of two very similar 35 microgram formulation COCs. Also, the average age of the subjects was younger than that of a typical gynecologic clinic population because this study was conducted at four Planned Parenthood sites. Of the 458 subjects, $406(89 \%)$ were under 30 years of age. ${ }^{15}$

The relationship between the use of depot medroxyprogesterone acetate and cervical neoplasia was examined in a case-control study in Costa Rica. Subjects were women with either confirmed invasive squamous cell neoplasia $(\mathrm{N}=149)$ or CIS $(\mathrm{N}=415)$. Logistic regression models which included "ever having used" depot medroxyprogesterone acetate as well as age were used to uncover confounding effects of socioeconomic status, gravidity, use of Pap testing, age at coitarche, history of sexually transmitted infection, tobacco use, condom or oral contraceptive use, pelvic inflammatory history, marital status, douching, education or geographic region differences. Ever having used depot medroxyprogesterone acetate was associated with a risk of CIS of $1.1(95 \%$ CI 0.6-1.8) and a risk of invasive neoplasia of 1.4 (95\% CI 0.6-3.1). Neither duration of time exposure to progesterone nor length of time from either first or last use of the hormone was noted to have a significant pattern of CIS risk. The authors did note a small increased risk for those women whose first use of depot medroxyprogesterone acetate occurred after age 39 (risk of 2.0, 95\% CI 0.8-5.5) when compared to women whose first 
use was before age 30 (risk of $0.6,95 \%$ CI $0.3-1.7$ ). The authors noted that the slightly elevated risks detected may have been the result of either detection bias or chance. A limitation of this study was that very few women in the study had used the depot medroxyprogesterone for a period of time longer than two years. Also, all estimates for invasive neoplasia were based on only 10 cases who reported use of depot medroxyprogesterone acetate. ${ }^{93}$

A New Zealand study on long term progesterone injection use noted that women with cervical dysplasia were more likely to have been using progesterone contraceptive injections prior to the development of the dysplasia compared to those who did not use progesterone injections. However, the researchers disclosed that the difference in results could be explained by the fact that women who used progesterone injections had very different sexual profiles than did the women who did not use progesterone injections. They tended to be younger at coitarche, have a greater number of lifetime sexual partners, and had a higher prevalence of cigarette smoking. ${ }^{94}$

A case-control trial conducted in a population of Jamaican women $(\mathrm{N}=338)$, noted use of hormonal contraception was associated both with dysplasia, (OR, 1.92 (CI $1.11,3.34 ; \rho=0.02)$ and severity of the dysplasia (OR, 2.22 (CI 1.05, 4.66) $\rho=0.036$ ). Hormonal contraception no longer retained significance when both alcohol consumption and parity were added to the model. The association with high risk cervical disease was retained when age and number of sexual partners were controlled. Depot medroxyprogesterone acetate use (with age and number of sexual partners as covariates) was also associated with dysplasia (OR, 2.43 (CI 1.39, 4.57), $\rho=0.006)$ and severity of disease (OR $2.51(1.11,5.64) \rho=0.027)$. Depot medroxyprogesterone acetate use remained significant with parity and alcohol added to this model. Exposure to hormonal contraception for greater than four years resulted in higher risk for disease, as well as greater severity of disease. ${ }^{95}$ The sample was homogenous, all of Jamaican descent. Hormonal contraception also included various forms and delivery systems of hormonal contraception. The IUD group was not further delineated into copper or progesterone system. The sample was all women presenting to colposcopy clinic who already had received an abnormal cytology result. The subjects had existing documented cervical pathology, thus the effect of depot medroxyprogesterone acetate on women infected with HPV, who did not yet exhibit dysplasia, could not be measured. ${ }^{95}$

\section{Progesterone Effect on Cervical Cells}

The cellular effects of endogenous hormones are variable. Cellular changes that occur with menopause or pregnancy have been well documented in the literature. In contrast, there has been relatively little work done looking specifically at the cellular effect of progesterone only contraceptives, particularly the progesterone only intrauterine device (Mirena $\left.{ }^{\circledR}\right)$. The existing literature is conflicting in nature.

One of the first papers to describe a cellular effect of progesterone on cervical cells was that of Bonte et al. ${ }^{96}$ A shift in the cellular pattern was noted in 100 women who were administered depot medroxyprogesterone. Cervical cells of a woman who has gone 
through menopause are normally predominantly atrophic or parabasal in nature. A predominantly parabasal cell pattern was noted in the cytologic samples of the Bonte et al. study group. ${ }^{96}$ This atrophic cellular appearance has subsequently been documented in women using depot medroxyprogesterone. ${ }^{17,97}$ Progesterone is thought to promote atrophy of the epithelial cells, as well as to decrease the cellular maturation pattern. ${ }^{5,33}$

Cellular characteristics associated with the effect of progesterone exposure include curling or crowding of squamous cells, destruction of cells, and unusual morphology to cells (navicular or classically called "boat shaped"). Curling is described as a rounding or rolling of cervical cellular edges, while crowding has been defined as more than four cells in a closely spaced grouping. Navicular cells have a classic "boat" shape, as well as having curled cellular edges and centralized glycogen content. ${ }^{16}$ Kaptain et al. (2002) reviewed 157 cervical smears: 50 from depot medroxyprogesterone users, 55 from women using COC, (Tri-Phasil $®$ ) and 51 from post-menopausal women. ${ }^{16} \mathrm{~A}$ definitive progesterone effect on the cells was noted. What was particularly of interest was that the anticipated progesterone effects of cellular crowding and curling were noted in both the combined progesterone and estrogen group and the depot medroxyprogesterone group (as compared to the post-menopausal group), but to a lesser extent in the depot medroxyprogesterone group than the COC group. Rates of cytolysis were similar among the COC and the depot medroxyprogesterone groups, though no cytolysis was noted in the post-menopausal group. The authors concluded that the progesterone effects were present more often in the COC group as compared to the depot medroxyprogesterone group. Both of the hormonal groups exhibited the progesterone cellular effects more so than the menopausal comparison group. The authors also noted that the duration of use of depot medroxyprogesterone did not have an effect on maturation of the squamous cells, which was thought to have been an issue with accurate interpretation. Part of the cellular evaluation in this study involved the use of a cellular maturational "perception scale," as devised by the authors, which differs from a maturational index (used by others). A cellular maturational perception scale may have different cellular categories to describe cellular changes, as compared to a maturational index scale. Maturation indexes are considered to be an objective method of classifying proportions of cells which are present in a given sample. ${ }^{98}$

In contrast, Valente and colleagues used a maturational index value (MV) to examine the cytology samples of 29 women whose average time using depot medroxyprogesterone was 22.6 months, comparing them to a group of 25 nonprogesterone exposed women. ${ }^{17}$ The authors did note a significantly lower MV for the progesterone use group, as compared to the non-progesterone use group (38.45 versus $64.60, \mathrm{p}<0.001) .{ }^{17}$ Of note, $16 \%$ of the cytologic specimens were graded as abnormal by the pathologist in the non-progesterone use group, whereas $21 \%$ were graded as abnormal in the progesterone exposed group. One LSIL result was confirmed as a low grade lesion in the progesterone use group, while three ASCUS result cytology specimens had a negative cytology result and/or histology at follow up. Two of the cytology samples in the progesterone user group were actually deemed as HSIL, but were noted to be negative in follow up cytology and/or biopsy. Two of the women in the non-progesterone use group who had HSIL results actually had a positive histology or cytologic test at follow 
up. One woman with an ASCUS cytology result had a negative cytology test at follow up. The cellular changes associated with progesterone did create a degree of difficulty in correctly interpreting the cytology sample. Kaptain et al. (2001) noted that the cellular pattern on cytology samples from menopausal women, which was mostly parabasal in cell type, was distinctively different from the intermediate cellular pattern noted in cytology samples from both the COC group and the depot medroxyprogesterone. ${ }^{16}$ Valente et al. (1998) argued that the cellular progesterone effects led to difficulty in accurate cytologic interpretation, ${ }^{17}$ but the findings of Kaptain et al. (2001) did not corroborate Valente et al's findings. Kaptain's study compared the progesterone users to either women using one formulation of a COC (Triphasil@) to women who were menopausal. Valente's study compared depot medroxyprogesterone users to women who were non-progesterone exposed. The comparison groups were not the same in both studies, which could account for the difference in findings. Also, Valente and colleagues used a maturational index value to assess the samples in their study, which Kaptain et al. did not use. The use of a scale to assess cellular maturation could affect the classification of cellular changes in one study, not necessarily accounted for in a study where the same scale is not used. ${ }^{16,17}$

Similar conflicting findings were noted by Knowles and Turbat-Herrera (1998) ${ }^{99}$ and Zhu and Wilbur (1998). ${ }^{100}$ Knowles and Turbat-Herrera noted a greater number of cellular abnormalities in the cytologic samples of women using depot medroxyprogesterone (across the spectrum of squamous intraepithelial lesion), compared to a matched control group (57.1\% versus $23.8 \%$ ), while Zhu and Wilbur (1998) did not note any increased rate of ASCUS preceded SIL in women using progesterone only contraception, when compared to a control group of women with ASCUS. ${ }^{101,102}$ Zhu and Wilbur (1998) ${ }^{100}$ only used conventionally prepared glass slide cytologic sampling, as opposed to liquid cytology sampling. The recognition was made that nucleus/cytoplasmic ratios, which is a primary indicator of dysplasia, may undergo alteration when exposed to a liquid cytology medium, as compared to cells fixed on the traditional glass slide (without being first placed in a liquid medium). Knowles and Turbat-Herrera (1998) ${ }^{99}$ did not specify the cytology medium utilized in their study which could account for the difference in findings between these two studies. Another potential difference between these two study groups was that the Knowles and Turbat-Herrera study utilized subjects using depot medroxyprogesterone as the progesterone agent of exposure, whereas Zhu and Wilbur did not specify the progesterone agent that their subjects used other than to call it "progesterone therapy for contraception." There are multiple existing forms of "progesterone therapy for contraception," and these could have altered the results. ${ }^{100}$

Darwish et al.'s findings (2004) ${ }^{103}$ echo that of Kaptain et al. (2002) ${ }^{16}$ in one of the only studies to include an oral and implantable progesterone method study group. The study group was comprised of a subgroup of depot medroxyprogesterone users, a progesterone only oral pill group and an implantable progesterone implant group (no longer available as a contraceptive)., The progesterone exposure group had abnormal cervical cytology screening $19 \%$ of the time compared to a control group who were not exposed to any progesterone, but who did have a Cu-T 380A copper IUD in place for at least three years prior, who had $17.6 \%$ abnormal cytology screening. This finding was not 
significant. ${ }^{6,92}$ The caveat of this study is that the comparison group consisted only of women with a copper IUD in situ. The copper IUD may affect cervical cytology such that there are cervical changes that, like the progesterone, are more likely to be misinterpreted by the pathologist as abnormal. There would be no difference in cytologic interpretation between progesterone users and copper IUD users if that were the case.

An issue to be addressed is whether the false-positive cervical cytology rates differ for women using progesterone only contraceptive methods. Hoekstra et al. $(2006)^{104}$ noted no difference in false-positive rates between hormonal contraception users and non-hormonal contraception users. The false- positive rates among nonhormonal contraceptive users was $38 \%$ versus $33 \%$ among the hormonal contraception users. The literature varies on this issue; however, Drejet (1998) ${ }^{105}$ noted an increased epithelial cell abnormality rate in the cytologic samples of women using depot medroxyprogesterone, with a decreased confirmation of cervical dysplasia, suggesting that there may be a false positive phenomenon in the interpretation of samples from women using progesterone only methods. ${ }^{105}$ Conversely, Clark et al. $(2011)^{36}$ did not find a higher rate of false positive cytology results comparing COC users to women using depot medroxyprogesterone.

In summary, progesterone does have an effect on cervical cells. Progesterone induces atrophy and a pattern that is parabasal cell dominant, with the appearance of curling or crowding of squamous cells, destruction of cells, and navicular cell shape. The effect this altered pattern has on cytologic interpretation is less clear. There is evidence in the literature that these changes may induce difficulty in interpreting cytologic samples, ${ }^{105}$ though the literature is conflicting.

\section{Summary of the Chapter}

Accurate interpretation of cervical sampling is paramount to the correct diagnosis and treatment of cervical dysplasia and neoplasia. Factors which may affect accurate interpretation are important to investigate. The literature on adverse effects of progesterone on cervical cytology is minimal and conflicting as to whether changes in cell structure (cellular crowding, navicular shape change, atrophic changes) adversely affect the interpretation of the cytology sampling. The existing literature has also looked mainly at depot medroxyprogesterone. There is a gap in the knowledge regarding actual effect of progesterone on cytology, particularly in regards to the local effect of progesterone administered via exposure to the progesterone IUD (Mirena $\left.{ }^{\circledR}\right)$. The existing evidence is unclear as to definitive progesterone effect. 


\section{CHAPTER 3. METHODOLOGY}

\section{Overview}

The purpose of this study was to examine the accuracy of cervical cytologic findings in women who were using either one of two forms of progesterone only contraception, depot medroxyprogesterone acetate injection or the progesterone IUD, as compared to women who either used a non-hormonal form of contraception, or no contraception at all. Accuracy, for the purposes of this study, was defined as the association between cytology interpretation and histology interpretation. A secondary purpose of the study was to investigate whether the length of time of progesterone exposure had an effect on the association between cytologic and histologic findings. In this chapter, the methodology is outlined to include research design, sampling, method of data retrieval and procedure, measurements, and analysis.

\section{Research Design}

A non-experimental retrospective design was used for this descriptive study. The database used for the study was the Synthetic Derivative (SD) electronic medical record base from Vanderbilt University Medical Center (VUMC), which is a de-identified copy of the main hospital medical record databases created for research purposes.

\section{Sample}

Institutional Review Board approval was obtained at both Vanderbilt University and the University of Tennessee Health Science Center. The SD database is a research database developed at Vanderbilt University to facilitate studies using de-identified clinical data. Consent for an individual's medical record inclusion into the SD is obtained when patients are seen at any of the Vanderbilt associated clinics and facilities. The database contains a total of 1.7 million patient records, with highly detailed longitudinal clinical data for approximately one million subjects, with an average clinical record size of 106,727 bytes and an average of 13 distinct International Classification of Disease, 9th revision codes (ICD-9) per record. The database incorporates data from multiple sources and includes diagnostic (ICD-9) and current procedural terminology (CPT) codes, basic demographics (age, gender, race), text from clinical care including discharge summaries, nursing notes, progress notes, history and physical, problem lists and multi-disciplinary assessments, laboratory values, electrocardiogram (ECG) diagnoses, clinical text and electronically derived trace values, and inpatient medication orders. The de-identification of the records is achieved through the application of a commercial electronic program, which is applied and assessed for acceptable effectiveness in scrubbing identifiers. All clinical data are updated regularly to include the addition of both new patients to the database, as well as appending of existing records. Thus, the resource is suitable for mining information relative to disease progression over time. 
The SD is stored on a secure server housed in the Vanderbilt Data Center and is fully compliant with the administrative, physical, and technical provisions of the Health Insurance Portability and Accountability Act (HIPAA) Security and Privacy Rules. The SD database is hosted on a Sun Solaris Server and running on Oracle 10g Software. The $\mathrm{SD}$ is mirrored by fully redundant server architecture in the event of a production server failure. Simple queries to the Synthetic Derivative (the number of records which meet certain criteria) are available by a user interface hosted on the VUMC intranet. For this study, custom datasets were created through a formal request submitted to the BioVU office at Vanderbilt University. There was no threat to confidentiality, as all participant records had been de-identified prior to inclusion in the synthetic derivative database, which was in compliance with the HIPAA guidelines for electronic data. There were no other potential risks identified.

Inclusion criteria for the study included women less than 60 years of age with an abnormal cervical cytologic report or abnormal histology report at colposcopy, who were:

- Using the levonorgestrel intrauterine device (Mirena $\left.{ }^{\circledR}\right)$ for at least six completed months prior to abnormal cytology/histology result, or;

- Using the depot medroxyprogesterone injection $150 \mathrm{mg}$ dose (Depo Provera ${ }^{\circledR}$ ) for at least six completed months prior to abnormal cytology/histology result, or;

- Using non-hormonal contraception for at least six completed months prior to abnormal cytology/histology result, or;

- Using no contraception for at least six completed months prior to abnormal cytology/histology result.

Exclusion criteria for the study were:

- Women who used combined oral contraception (containing both estrogen and progesterone).

- Current pregnant or post-menopausal status.

- Women who met the inclusion criteria, but did not have either a cervical biopsy or an endocervical curettage done at colposcopy.

- Women who were not using any contraception, but who had used a progesterone containing contraceptive up to, but not including the six months prior to, the abnormal cytology result were excluded.

Levonorgestrel IUD is a five year product, so records of individuals using Mirena ${ }^{\circledR}$ were searched for the 6 years prior to abnormal cytology results. Going back at least six years from the time of the colposcopy procedure would capture the insertion procedures of the IUD. This was important to be able to capture subjects who had the IUD in situ, whose records did not make mention of it after the initial insertion. A period of five years prior to abnormal cytology was chosen to go back into the progesterone injection user's records to be able to capture those records wherein a woman may have been using the medication at the time of colposcopy, but inadvertently did not have 
mention of it in her record. Of note, women with ASCUS cytology results, without accompanying HPV results, were retained as subjects. Women who had an ASCUS HPV negative cytology result were referred to colposcopy prior to the release of the 2006 abnormal cytology guidelines and the use of reflex HPV testing. Repeat cytology in one year is the current recommendation with an ASCUS HPV negative result, rather than colposcopy. Practitioners recommend colposcopy if ASCUS persists beyond one year. ${ }^{36}$ Cytology results of ASCUS with a negative accompanying HPV remained in the inclusion criteria for abnormal cytology because it is classified as an abnormal result.

The first two inclusion criteria entered to search the database were females less than 60 years of age with one or more of the following CPT codes (for varying types of colposcopy): $57452,57454,57455,57456,57460$, or 57461 . Records were excluded that mentioned any of the excluded COCs. Also excluded were subjects who were currently pregnant, or pregnant within the preceding 9 months or those with ICD-9 codes of V22 or V23 (pregnancy) within the nine months prior to the colposcopy. The three study sets were constructed from this initial group of records.

Group 1 included all records which met the criteria mentioned previously, and excluded every record in set 2 or 3 . Group 2 included everything that met criteria for set 1 , as well as having to have had a mention of Mirena ${ }^{\circledR}$ OR Levonorgestrel or CPT J7302 within six years prior to the colposcopy CPT dates. Group 3 included all of those records that met criteria for set 1 , with the added requisite that there had to have been a mention of one or more of the following medications (Depo Provera ${ }^{\circledR}$ or Depot Provera ${ }^{\circledR}$ OR depot medroxyprogesterone) or CPT codes for them (J1055), within five years prior to the colposcopy CPT date. Dataset 1 contained 6,515 records, dataset 2 contained 142 records, and dataset 3 contained 470 records. A final group of all progesterone users was formed for the purposes of analysis which contained the records of those in groups 2 and 3.

\section{Setting and Recruitment}

A large academic medical center located in Nashville, Tennessee was the origination site for the SD. Recruitment of subjects was accomplished via the submission of specific search data into the database as described in the sampling section. The study received exempt review status from both Institutional Review Boards.

\section{Procedures}

The SD was accessed via secure login and password. The records had been loaded into the database by the BioVu office after they were formed. The anatomical pathology portion of each record was examined to ensure that a cervical biopsy had been done following the abnormal cytology result. The record was omitted from use if neither a cervical histology sample, nor an endocervical curettage had been collected. Demographic data, cytology and corresponding histology results were recorded in a Microsoft Excel ${ }^{\circledR}$ formatted codebook after the record was verified for the presence of a 
histology sample. Every record in both the IUD group and the progesterone injection group was examined. Records in the non-hormonal-no contraception group were reviewed and added until the sample size was comparable to the progesterone injection group

Data cleaning occurred prior to analysis. Records were excluded for the following reasons: 94 had no histologic specimen collected after the abnormal cytology result; 40 had no abnormal cytology result preceding colposcopy; 30 progesterone injection users could not be verified for length of use of the injection; 21 did not have contraceptive type recorded; eight were using COC at the time of the abnormal cytology result; six were pregnant at the time of the cytologic screening; six records did not indicate how long the progesterone IUD had been in situ: four used the combined contraceptive patch, one did not have the IUD in at least six months; one had colposcopy done only as result of abnormal endometrial biopsy and not abnormal cytology result; one had no cytology result in the chart; one had no histology result in the chart, one cytology screening was done post hysterectomy, and whether ovaries were removed could not be verified; and one cytology screening was done after hysterectomy with no subsequent histology collection. This resulted in the following sample sizes: group one equaled 72, group two equaled 35 and group three equaled 73 . The final group, which combined groups two and three equaled 108. All data were exported into Statistical Package for the Social Sciences, Statistics Data Editor (SPSS) version 19. ${ }^{106}$

\section{Data Analysis}

Descriptive data included age, race, marital status, gravida and parity, smoking status, years of tobacco use and amount used, contraceptive use and type used, abnormal cytologic sample result type and resultant histology typing. Time lapse between the abnormal cytologic screen report and the subsequent colposcopy was recorded, as well as the amount of time the participant had been using the progesterone product, if applicable. Chi square analysis was performed to evaluate variations in the proportions of women in each group (the progesterone IUD group, the progesterone injection group and the nonprogesterone use group).

\section{Coding for Analysis}

Cytology results were collapsed and recoded as an ordinal variable (low, high). Histology results were also collapsed and recoded as an ordinal variable (neg, low, high). Collapsing results in this manner is consistent with Bethesda System 2001 for combining moderate and severe dysplasia and is historically, and currently, how these results are collapsed for purpose of research. If groups had not been collapsed for the purpose of analysis, the cells for each individual cytology and histology combination would have been too small for analysis. Therefore, all of the following cytology results were collapsed into group 1 (low grade): ASCUS without HPV result; ASCUS, HPV positive; ASCUS, HPV negative; and LSIL. All of the following were collapsed into group 2 (high grade): HSIL, AGC, ASCUS-H, and LSIL-H. Histology and endocervical curettage 
results were collapsed into three categories. Histology results that were negative were coded as group 0 (Table 3-1). Group 1 (low grade) contained: cervicitis and CIN I histology results. All of the following were collapsed into group 2 (high grade): CIN II; CIN III; CIS; invasive neoplasia and glandular adenocarcinoma.

Research questions two and three dealt with the relationship between cytology and histology. Chi square analysis was undertaken to address these questions. The first step involved analyzing the association between cytology and histology by progesterone exposure per group, and comparing no progesterone exposure to those who had any progesterone exposure. The second step looked at agreement by either agree/disagree by type of progesterone exposure first, and then by either no progesterone exposure or any progesterone exposure. The latter half of that analysis examined the cytology/histology relationship using the terms agree, false negative or false positive, according to type of progesterone exposure, and then any exposure versus no exposure.

A new outcome variable was then created to describe the relationship between cytology and histology in the four groups of subjects in order to analyze agreement between results of cytology and histology by progesterone exposure. This particular portion of the analysis was something that has not been seen previously, and is unique to this study. Creation of a new defining outcome variable allowed for a greater degree of discrimination in determining the relationship between cytology and histology. The first level agreement variable was defined simply as the discrete "agree," (yes or no) and was applied to the cytology/histology relationship in terms of whether the particular relationship was consistent with what would be expected, or not. The second level of agreement consisted of the discrete variables of "agree," "false negative," or "false positive," for every combination of cytology and histology result (Table 3-2). An "agree" by definition meant that the histology result was consistent with what would be expected from the preceding cytology result. A "false positive" existed if the cytology result was at a greater level of abnormality than the corresponding histology result. A "false negative" existed when the cytology result was a lesser degree of abnormal than the subsequent histology result.

The new defining outcome variable added greater depth of understanding of the relationship between cytology and histology. The nuances that occur within the low and high grade cytology/histology pairings would not be accounted for if analysis had ceased with the collapsing of cytology and histology into simply low grade and high grade groupings. The assumption would be, for example, that a cytology result in the low grade category, paired with a subsequent histology result also in the low grade category would represent an agree relationship between the cytology and histology. However, there are three cytology/histology combinations within the low grade pairings which actually represent a false positive, rather than an agreement situation. There are also three cytology/histology combinations that represent false negative in the high grade cytology and histology combinations. 
Table 3-1. Categorization of cytology and histology results into collapsed categories

\begin{tabular}{lccc}
\hline $\begin{array}{l}\text { Cytology results } \\
\text { collapsed into low } \\
\text { grade category }\end{array}$ & $\begin{array}{c}\text { Cytology results } \\
\text { collapsed into high } \\
\text { grade category }\end{array}$ & $\begin{array}{c}\text { Histology results } \\
\text { collapsed into low } \\
\text { grade category }\end{array}$ & $\begin{array}{c}\text { Histology results } \\
\text { collapsed into high } \\
\text { grade category }\end{array}$ \\
\hline ASCUS without & HSIL & Cervicitis & CIN II \\
HPV & AGC & CIN I & CIN III \\
ASCUS HPV & ASCUS-H & & CIS \\
positive & LSIL-H & & Invasive neoplasia \\
ASCUS HPV & & & Glandular \\
negative & & & Adenocarcinoma \\
LSIL & & & \\
\hline
\end{tabular}

Abbreviations: ASCUS without HPV, atypical squamous cells of undetermined significance with no human Papilloma virus test result; ASCUS HPV positive, atypical squamous cells of undetermined significance with a positive human Papilloma virus test result; ASCUS HPV negative, atypical squamous cells of undetermined significance with a negative human Papilloma virus test result; LSIL, low grade squamous intraepithelial lesion; HSIL, high grade squamous intraepithelial lesion; AGC, atypical glandular cells; ASCUS-H, atypical squamous cells of undetermined significance, cannot rule out high grade; LSIL-H, low grade squamous intraepithelial lesion, cannot rule out high grade; CIN, cervical intraepithelial neoplasia; CIS, carcinoma in situ. 
Table 3-2. Definition of agreement between cytology and histology

\begin{tabular}{|c|c|c|c|c|c|c|c|c|}
\hline Pap biopsy/ECC & $\begin{array}{l}\text { ASCUS } \\
\text { no HPV }\end{array}$ & $\begin{array}{c}\text { ASCUS } \\
\text { HPV neg }\end{array}$ & $\begin{array}{c}\text { ASCUS } \\
\text { HPV pos }\end{array}$ & LSIL & HSIL & AGC & ASCUS-H & LSIL-H \\
\hline Negative & Agree & Agree & $\begin{array}{c}\text { False } \\
\text { positive }\end{array}$ & $\begin{array}{c}\text { False } \\
\text { positive }\end{array}$ & $\begin{array}{c}\text { False } \\
\text { positive }\end{array}$ & $\begin{array}{c}\text { False } \\
\text { positive }\end{array}$ & $\begin{array}{c}\text { False } \\
\text { positive }\end{array}$ & $\begin{array}{c}\text { False } \\
\text { positive }\end{array}$ \\
\hline Cervicitis & Agree & Agree & Agree & $\begin{array}{c}\text { False } \\
\text { positive }\end{array}$ & $\begin{array}{c}\text { False } \\
\text { positive }\end{array}$ & $\begin{array}{c}\text { False } \\
\text { positive }\end{array}$ & $\begin{array}{c}\text { False } \\
\text { positive }\end{array}$ & $\begin{array}{c}\text { False } \\
\text { positive }\end{array}$ \\
\hline CIN I & Agree & Agree & Agree & Agree & $\begin{array}{c}\text { False } \\
\text { positive }\end{array}$ & $\begin{array}{c}\text { False } \\
\text { positive }\end{array}$ & Agree & Agree \\
\hline CIN II & $\begin{array}{c}\text { False } \\
\text { negative }\end{array}$ & $\begin{array}{c}\text { False } \\
\text { negative }\end{array}$ & $\begin{array}{c}\text { False } \\
\text { negative }\end{array}$ & $\begin{array}{c}\text { False } \\
\text { negative }\end{array}$ & Agree & Agree & Agree & Agree \\
\hline CIN III & $\begin{array}{c}\text { False } \\
\text { negative }\end{array}$ & $\begin{array}{c}\text { False } \\
\text { negative }\end{array}$ & $\begin{array}{c}\text { False } \\
\text { negative }\end{array}$ & $\begin{array}{c}\text { False } \\
\text { negative }\end{array}$ & Agree & Agree & Agree & Agree \\
\hline CIS & $\begin{array}{c}\text { False } \\
\text { negative }\end{array}$ & $\begin{array}{c}\text { False } \\
\text { negative }\end{array}$ & $\begin{array}{c}\text { False } \\
\text { negative }\end{array}$ & $\begin{array}{c}\text { False } \\
\text { negative }\end{array}$ & Agree & Agree & Agree & Agree \\
\hline Invasive CA & $\begin{array}{c}\text { False } \\
\text { negative }\end{array}$ & $\begin{array}{c}\text { False } \\
\text { negative }\end{array}$ & $\begin{array}{c}\text { False } \\
\text { negative }\end{array}$ & $\begin{array}{c}\text { False } \\
\text { negative }\end{array}$ & Agree & Agree & Agree & Agree \\
\hline Adenocarcinoma & $\begin{array}{c}\text { False } \\
\text { negative }\end{array}$ & $\begin{array}{c}\text { False } \\
\text { negative }\end{array}$ & $\begin{array}{c}\text { False } \\
\text { negative }\end{array}$ & $\begin{array}{c}\text { False } \\
\text { negative }\end{array}$ & $\begin{array}{c}\text { False } \\
\text { negative }\end{array}$ & Agree & $\begin{array}{c}\text { False } \\
\text { negative }\end{array}$ & $\begin{array}{c}\text { False } \\
\text { negative }\end{array}$ \\
\hline
\end{tabular}

Abbreviations: ECC, endocervical curetage; ASCUS no HPV, atypical squamous cells of undetermined significance with no human Papilloma virus test result; ASCUS HPV pos, atypical squamous cells of undetermined significance with a positive human Papilloma virus test result; ASCUS HPV neg, atypical squamous cells of undetermined significance with a negative human Papilloma virus test result; LSIL, low grade squamous intraepithelial lesion; 


\section{Table 3-2. (Continued)}

HSIL, high grade squamous intraepithelial lesion; AGC, atypical glandular cells; ASCUS-H, atypical squamous cells of undetermined significance, cannot rule out high grade; LSIL-H, low grade squamous intraepithelial lesion, cannot rule out high grade; CIN, cervical intraepithelial neoplasia; CIS, carcinoma in situ. 


\section{Analysis for Individual Questions}

Statistical methods used in this study included measures of central tendency including means, ranges and standard deviations as well as Chi square analysis, and logistic regression. Descriptive analysis was run on each of the three groups independently, and then on the combined group of the IUD and injection group to address research question one. The continuous variable data collected included age, years smoked, amount smoked, gravid/parity, and length of time between Pap and subsequent biopsy. Categorical variable data collected included race, marital status, smoking status, history of prior abnormal cytology result, and history of prior cervical treatment.

Chi square analysis was run on the newly formed collapsed groups to address research question two. This was performed to evaluate the relationship between cytology findings and histology findings across the entire sample. This analysis was done to determine the relationship between cytology and histology results. Regrouping according to progesterone exposure was also necessary for the two Chi square analyses undertaken to analyze cytology/histology results by progesterone exposure. In the first Chi square analysis, subjects were either in the non-hormonal or no contraception group, the progesterone IUD group, or the progesterone injection group. In the second Chi square analysis undertaken to look at progesterone exposure, the subjects in either of the two progesterone groups (the IUD or the progesterone injection group) were collapsed into the progesterone group, and all others not exposed to progesterone were included in the no progesterone group.

Four Chi square analyses were run to answer research question three. Results were then compared across the groups to determine if there was a difference in the relationship between cytology and histology in groups of women with abnormal cytology test results. Two logistic regressions were undertaken in which the variables of time on progesterone, age, group (whether IUD or injection), and group by time on progesterone were analyzed for interaction to address research question four. Age was adjusted for in this analysis because it is realistic to supposed that the older a woman is, the greater the amount of time she could have theoretically been exposed to progesterone. The first regression model analyzed progesterone in the context of agree $(y / n)$, and the second in the context of false positive $(\mathrm{y} / \mathrm{n})$. 


\section{CHAPTER 4. RESULTS}

The purpose of this study was to examine the accuracy of cervical cytologic findings in women who were using either one of two forms of progesterone only contraception, as compared to women who used either a non-hormonal form of contraception or no contraception at all. Accuracy, for the purposes of this study, was defined as the association between cytology interpretation and histology interpretation. A secondary purpose of the study was to investigate whether the length of time of progesterone exposure had an effect on the association between cytologic and histologic findings.

\section{Research Question 1: What Are the Characteristics (Demographic, Gynecologic and Smoking History) of Four Groups of Women Who Have Abnormal Cytologic Test Results?}

\section{Characteristics of the sample}

Table 4-1 reports the characteristics of the sample for this study. Each of the three groups (no progesterone exposure, IUD users, and injection users) is included as well as a fourth group which was constructed by combining subjects with any progesterone exposure (the IUD and injection groups). There were 180 subjects who were between the ages of 14 and 79 years with a mean age of 27.5 years (SD \pm 7.2 ). Most subjects were either black (46.7\%) or white $(41.7 \%)$ and the remainder were Asian $(1.1 \%)$, Hispanic $(1.1 \%)$, other $(0.6 \%)$ or did not have a recorded race $(8.9 \%)$. Fortyeight $(26.7 \%)$ of subjects were married with the largest percentage of married women in the IUD group (45.7\%) and the lowest percentage $(15.1 \%)$ in the progesterone injection group Approximately one third of the subjects (30.6\%) smoked but this varied from a low of $22.2 \%$ for non-hormone/no contraception subjects to a high of $41.1 \%$ for injection progesterone uses. As noted in Table 4-1 there are similarities in the length of time smoking and amount smoked for the different groups.

The largest number of nulligravid women was in the progesterone injection group $(16.4 \%)$ and the smallest number $(11.4 \%)$ in the IUD group. Elapsed time between collection of Pap and subsequent colposcopy (in weeks) was greatest in the progesterone injection group (11.8 \pm 10.9$)$, and least in the non-hormonal/no contraception group $(6.9 \pm 7.6)$. Nearly half of the sample had a prior abnormal cytology result $(45.6 \%)$, and $12.8 \%$ had received prior cervical treatment for dysplasia. Prior treatment was either cold knife cone, cryotherapy or loop electrosurgery excision procedure.

\section{Frequency of cytologic and histologic abnormalities}

Table 4-2 reports the cytologic and histologic results by group. The most common cytology result among all subjects was LSIL (42.8\%) while the least common 
Table 4-1. Sample characteristics

\begin{tabular}{|c|c|c|c|c|c|}
\hline Characteristics & $\begin{array}{c}\text { Non-hormonal or } \\
\text { no contraception } \\
(\mathrm{n}=72)\end{array}$ & $\begin{array}{c}\text { Progesterone IUD } \\
\text { group } \\
(\mathrm{n}=\mathbf{3 5}) \\
\end{array}$ & $\begin{array}{c}\text { Progesterone } \\
\text { injection group } \\
(\mathrm{n}=73)\end{array}$ & $\begin{array}{l}\text { Combined IUD } \\
\text { and injection } \\
\text { group }(n=108)\end{array}$ & $\begin{array}{c}\text { All subjects in all } \\
\text { groups } \\
(\mathbf{n}=\mathbf{1 8 0}) \\
\end{array}$ \\
\hline Age $\mathbf{n} \pm \mathbf{S D}$ & $\begin{array}{c}28.1 \pm 7.8 \\
\text { range } 16-49\end{array}$ & $\begin{array}{c}28.5 \pm 5.8 \\
\text { range } 20-43\end{array}$ & $\begin{array}{c}26.3 \pm 7.1 \\
\text { range } 14-43\end{array}$ & $\begin{array}{c}27.0 \pm 6.8 \\
\text { range } 14-43\end{array}$ & $\begin{array}{c}27.5 \pm 7.2 \\
\text { range } 14-49\end{array}$ \\
\hline $\begin{array}{l}\text { Race n (\%) } \\
\text { White } \\
\text { Black } \\
\text { AI } \\
\text { Asian } \\
\text { Hawaiian/PI } \\
\text { Hispanic } \\
\text { Other } \\
\text { Unknown }\end{array}$ & $\begin{array}{c}35(48.6) \\
27(37.5) \\
0 \\
0 \\
0 \\
2(2.8) \\
1(1.4) \\
7(9.7)\end{array}$ & $\begin{array}{c}19(54.3) \\
10(28.6) \\
0 \\
0 \\
0 \\
0 \\
0 \\
6(17.1)\end{array}$ & $\begin{array}{c}21(28.8) \\
47(64.4) \\
0 \\
2(2.7) \\
0 \\
0 \\
0 \\
3(4.1)\end{array}$ & $\begin{array}{c}40(37.0) \\
57(52.8) \\
0 \\
2(1.9) \\
0 \\
0 \\
0 \\
9(8.3)\end{array}$ & $\begin{array}{c}75(41.7) \\
84(46.7) \\
0 \\
2(1.1) \\
0 \\
2(1.1) \\
1(0.6) \\
16(8.9)\end{array}$ \\
\hline $\begin{array}{l}\text { Marital status } \\
\text { n (\%) } \\
\text { Unmarried } \\
\text { Married } \\
\text { Divorced } \\
\text { Unknown }\end{array}$ & $\begin{aligned} 39 & (54.2) \\
21 & (29.2) \\
2 & (2.8) \\
10 & (13.9)\end{aligned}$ & $\begin{array}{c}15(42.9) \\
16(45.7) \\
3(8.6) \\
1(2.9)\end{array}$ & $\begin{aligned} 42 & (57.5) \\
11 & (15.1) \\
7 & (9.6) \\
13 & (17.8)\end{aligned}$ & $\begin{array}{c}57(52.8) \\
27(25.0) \\
10(9.3) \\
14(13.0)\end{array}$ & $\begin{array}{c}96(53.3) \\
48(26.7) \\
12(6.7) \\
24(13.3)\end{array}$ \\
\hline $\begin{array}{l}\text { Smoker n (\%) } \\
\text { Non-smoker } \\
\text { Smoker } \\
\text { Former } \\
\text { Unknown }\end{array}$ & $\begin{array}{c}38(52.8) \\
16(22.2) \\
6(8.3) \\
12(16.7)\end{array}$ & $\begin{array}{c}25(71.4) \\
9(25.7) \\
0 \\
1(2.9)\end{array}$ & $\begin{array}{c}33(45.2) \\
30(41.1) \\
0 \\
10(13.7)\end{array}$ & $\begin{array}{c}58(53.7) \\
39(36.1) \\
0 \\
11(10.2)\end{array}$ & $\begin{array}{c}96(53.3) \\
55(30.6) \\
6(3.3) \\
23(12.8)\end{array}$ \\
\hline $\begin{array}{l}\text { Years smoked } \\
\mathbf{n} \pm \mathbf{S D}\end{array}$ & $\begin{array}{c}6.3 \pm 6.6 \\
\text { range } 1-18\end{array}$ & $\begin{array}{c}10.3 \pm 7.5 \\
\text { range } 2-18\end{array}$ & $\begin{array}{c}7.7 \pm 7.0 \\
\text { range } 0-20\end{array}$ & $\begin{array}{c}8.7 \pm 6.9 \\
\text { range } 0-20\end{array}$ & $\begin{array}{c}7.8 \pm 6.7 \\
\text { range } 0-20\end{array}$ \\
\hline
\end{tabular}


Table 4-1. (Continued)

\begin{tabular}{|c|c|c|c|c|c|}
\hline Characteristics & $\begin{array}{c}\text { Non-hormonal or } \\
\text { no contraception } \\
(n=72) \\
\end{array}$ & $\begin{array}{c}\text { Progesterone IUD } \\
\text { group } \\
(\mathrm{n}=\mathbf{3 5})\end{array}$ & $\begin{array}{c}\text { Progesterone } \\
\text { injection group } \\
(n=73)\end{array}$ & $\begin{array}{l}\text { Combined IUD } \\
\text { and injection } \\
\text { group }(n=108)\end{array}$ & $\begin{array}{c}\text { All subjects in all } \\
\text { groups } \\
(\mathbf{n}=\mathbf{1 8 0}) \\
\end{array}$ \\
\hline $\begin{array}{l}\text { Amount } \\
\text { smoked } \\
n \pm \text { SD }\end{array}$ & $\begin{array}{c}12.9 \pm 9.0 \\
\text { range } 2-40\end{array}$ & $\begin{array}{l}13.0 \pm 5.3 \\
\text { range } 7-20\end{array}$ & $\begin{array}{l}17.2 \pm 12.3 \\
\text { range } 2-60\end{array}$ & $\begin{array}{l}16.1 \pm 11.0 \\
\text { range } 2-60\end{array}$ & $\begin{array}{l}15.0 \pm 10.3 \\
\text { range } 2-60\end{array}$ \\
\hline \multicolumn{6}{|l|}{ Gravida n (\%) } \\
\hline Nulligravid & $10(13.9)$ & $4(11.4)$ & $12(16.4)$ & $16(14.8)$ & $26(14.4)$ \\
\hline One & $21(29.2)$ & 17 (48.6) & $13(17.8)$ & $30(27.8)$ & $51(28.3)$ \\
\hline Two & $21(29.2)$ & $5(14.3)$ & $28(38.4)$ & $33(30.6)$ & $54(30)$ \\
\hline Three & $12(16.7)$ & $4(11.4)$ & $9(12.3)$ & $13(12)$ & 25 (13.9) \\
\hline Four & $4(5.6)$ & $4(11.4)$ & $6(8.2)$ & $10(9.3)$ & $14(7.8)$ \\
\hline Five & $2(2.8)$ & 0 & $2(2.7)$ & $2(1.9)$ & $4(2.2)$ \\
\hline Six & $1(1.4)$ & 0 & 0 & 0 & $1(0.6)$ \\
\hline \multicolumn{6}{|l|}{ Parity n (\%) } \\
\hline Nulliparous & $18(25)$ & $4(11.4)$ & $17(23.3)$ & $21(19.4)$ & $39(21.7)$ \\
\hline One & $23(31.9)$ & $17(48.6)$ & $22(30.1)$ & $39(36.1)$ & 62. (34.4) \\
\hline Two & $22(30.6)$ & $9(14.3)$ & $21(28.8)$ & $30(27.8)$ & $52(28.9)$ \\
\hline Three & $6(8.3)$ & $4(11.4)$ & $8(11.0)$ & $12(11.1)$ & $18(10)$ \\
\hline Four & $1(1.4)$ & 0 & 0 & 0 & $1(0.6)$ \\
\hline Five & $1(1.4)$ & 0 & $2(2.7)$ & $2(1.9)$ & $3(1.7)$ \\
\hline $\begin{array}{l}\text { Time between } \\
\text { cytology and } \\
\text { colposcopy } \\
\text { weeks } \pm \text { SD }\end{array}$ & $\begin{array}{c}6.9 \pm 7.6 \\
\text { range } 0-40\end{array}$ & $\begin{array}{c}7.4 \pm 7.3 \\
\text { range } 0-28\end{array}$ & $\begin{array}{l}11.8 \pm 10.9 \\
\text { range } 0-44\end{array}$ & $\begin{array}{l}10.4 \pm 10.0 \\
\text { range } 0-44\end{array}$ & $\begin{array}{c}9.0 \pm 9.3 \\
\text { range } 0-44\end{array}$ \\
\hline
\end{tabular}


Table 4-1. (Continued)

\begin{tabular}{|c|c|c|c|c|c|}
\hline Characteristics & $\begin{array}{c}\text { Non-hormonal or } \\
\text { no contraception } \\
(\mathrm{n}=72) \\
\end{array}$ & $\begin{array}{c}\text { Progesterone IUD } \\
\text { group } \\
(\mathrm{n}=\mathbf{3 5}) \\
\end{array}$ & $\begin{array}{c}\text { Progesterone } \\
\text { injection group } \\
(n=73)\end{array}$ & $\begin{array}{l}\text { Combined IUD } \\
\text { and injection } \\
\text { group }(n=108)\end{array}$ & $\begin{array}{c}\text { All subjects in all } \\
\text { groups } \\
(\mathbf{n}=\mathbf{1 8 0})\end{array}$ \\
\hline \multicolumn{6}{|l|}{$\begin{array}{l}\text { History of prior } \\
\text { abnormal } \\
\text { cytology n }(\%)\end{array}$} \\
\hline No & $45(62.5)$ & $19(54.3)$ & $31(42.5)$ & $50(46.3)$ & $95(52.8)$ \\
\hline Yes & $25(34.7)$ & $15(42.9)$ & $42(57.5)$ & $57(52.8)$ & $82(45.6)$ \\
\hline Unknown & $2(2.8)$ & $1(2.9)$ & 0 & $1(0.9)$ & $3(1.7)$ \\
\hline \multicolumn{6}{|l|}{$\begin{array}{l}\text { History of } \\
\text { cervical } \\
\text { treatment } \\
n(\%)\end{array}$} \\
\hline No & $63(87.5)$ & $30(85.7)$ & $60(82.2)$ & $90(83.3)$ & $153(85)$ \\
\hline Yes & $7(9.7)$ & $4(11.4)$ & $12(16.4)$ & $16(14.8)$ & $23(12.8)$ \\
\hline Unknown & $2(2.8)$ & $1(2.9)$ & $1(1.4)$ & $1(1.9)$ & $4(2.2)$ \\
\hline
\end{tabular}


Table 4-2. Cytology result, cervical histology result, and endocervical curettage result by progesterone exposure $(n=180)$

\begin{tabular}{|c|c|c|c|c|c|}
\hline Results & $\begin{array}{l}\text { Non-hormonal or } \\
\text { no contraception } \\
\quad(n=72)\end{array}$ & $\begin{array}{c}\text { Progesterone } \\
\text { IUD } \\
(n=35)\end{array}$ & $\begin{array}{c}\text { Progesterone } \\
\text { injection } \\
(n=73)\end{array}$ & $\begin{array}{l}\text { Total all } \\
\text { subjects } \\
(n=180)\end{array}$ & $\begin{array}{c}\text { Progesterone } \\
\text { exposure by either } \\
\text { IUD or injection } \\
(n=108)\end{array}$ \\
\hline \multicolumn{6}{|l|}{$\begin{array}{l}\text { Cytology result } \\
\text { n (\%) }\end{array}$} \\
\hline ASCUS no HPV & 0 & 1 & 5 & 6 & 6 \\
\hline ASCUS HPV - & 0 & 0 & 1 & 1 & 1 \\
\hline ASCUS HPV + & 17 & 8 & 8 & 33 & 16 \\
\hline ASCUS-H & 3 & 3 & 5 & 11 & 8 \\
\hline LSIL & 30 & 14 & 33 & 77 & 47 \\
\hline LSIL-H & 1 & 1 & 1 & 3 & 2 \\
\hline HSIL & 17 & 8 & 17 & 42 & 25 \\
\hline $\mathrm{AGC}$ & 4 & 0 & 3 & 7 & 3 \\
\hline \multicolumn{6}{|l|}{$\begin{array}{l}\text { Histology result } \\
\text { n (\%) }\end{array}$} \\
\hline Neg & 12 & 9 & 10 & 31 & 19 \\
\hline Cervicitis & 10 & 6 & 14 & 30 & 20 \\
\hline CIN I & 21 & 10 & 20 & 51 & 30 \\
\hline CIN II & 8 & 6 & 9 & 23 & 15 \\
\hline CIN III & 6 & 0 & 6 & 12 & 6 \\
\hline CIS & 0 & 0 & 0 & 0 & 0 \\
\hline Invasive CA & 0 & 0 & 0 & 0 & 0 \\
\hline Adenocarcinoma & 0 & 0 & 0 & 0 & 0 \\
\hline Not done & 15 & 4 & 14 & 33 & 18 \\
\hline
\end{tabular}


Table 4-2. (Continued)

\begin{tabular}{|c|c|c|c|c|c|}
\hline Results & $\begin{array}{c}\text { Non-hormonal or } \\
\text { no contraception } \\
(n=72)\end{array}$ & $\begin{array}{c}\text { Progesterone } \\
\text { IUD } \\
(\mathbf{n}=\mathbf{3 5})\end{array}$ & $\begin{array}{c}\text { Progesterone } \\
\text { injection } \\
(n=73)\end{array}$ & $\begin{array}{l}\text { Total all } \\
\text { subjects } \\
(n=180)\end{array}$ & $\begin{array}{c}\text { Progesterone } \\
\text { exposure by either } \\
\text { IUD or injection } \\
(\mathrm{n}=\mathbf{1 0 8})\end{array}$ \\
\hline \multicolumn{6}{|l|}{$\begin{array}{l}\text { Endocervical } \\
\text { curettage result } \\
\text { n }(\%)\end{array}$} \\
\hline Neg & 34 & 19 & 39 & 92 & 58 \\
\hline Cervicitis & 0 & 0 & 0 & 0 & 0 \\
\hline CIN I & 0 & 0 & 0 & 0 & 0 \\
\hline CIN II & 1 & 0 & 1 & 2 & 1 \\
\hline CIN III & 0 & 0 & 1 & 1 & 1 \\
\hline CIS & 0 & 0 & 0 & 0 & 0 \\
\hline Invasive CA & 0 & 0 & 0 & 0 & 0 \\
\hline Adenocarcinoma & 0 & 0 & 0 & 0 & 0 \\
\hline Not done & 37 & 16 & 32 & 85 & 48 \\
\hline $\begin{array}{l}\text { Time on } \\
\text { progesterone } \\
\text { months } \pm \text { SD }\end{array}$ & NA & $\begin{array}{c}20.4 \pm 13.6 \\
\text { range } \\
6-60\end{array}$ & $\begin{array}{c}27.9 \pm 22.6 \\
\text { range } \\
5-168\end{array}$ & NA & $\begin{array}{c}25.5 \pm 20.4 \\
\text { range } 5-168\end{array}$ \\
\hline
\end{tabular}

Abbreviations: ASCUS no HPV, atypical squamous cells of undetermined significance with no human Papilloma virus test result; ASCUS HPV +, atypical squamous cells of undetermined significance with a positive human Papilloma virus test result; ASCUS HPV -, atypical squamous cells of undetermined significance with a negative human Papilloma virus test result; LSIL, low grade squamous intraepithelial lesion; HSIL, high grade squamous intraepithelial lesion; AGC, atypical glandular cells; ASCUS-H, atypical squamous cells of undetermined significance, cannot rule out high grade; LSIL-H, low grade squamous intraepithelial lesion, cannot rule out high grade; CIN, cervical intraepithelial neoplasia; CIS, carcinoma in situ. 
was ASCUS high risk HPV negative (0.6\%). Table 4-2 shows the differences within group for the various results.

\section{Research Question 2: What is the Relationship between Cytology and Histology in Four Groups of Women with Abnormal Cytology Results?}

Answering Research Question 2 required that certain components of the data had to be collapsed. The cytology results were collapsed into the low grade group (ASCUS no HPV result, ASCUS HPV positive, ASCUS HPV negative, and LSIL) and a high grade group (HSIL, AGC, ASCUS-H and LSIL-H). Similarly, the histology results were collapsed into three groups of negative, low grade (Cervicitis, CIN I) and high grade (CIN II, CIN III, CIS, Invasive neoplasia and Glandular Adenocarcinoma). Table 4-3 shows the cross tabulation of these groups. These groups were then analyzed by the use of Somers' D, which is used to analyze association between two ordinal variables (cytology and histology). A significant relationship $(p=0.008)$, was found between results of cytology and histology samples.

The results were then analyzed by evaluating various levels of progesterone exposure for the subjects. Tables 4-4 through 4-7 show the results of these analyses. Again, the data were collapsed as described in Table 4-3. Table 4-4 shows the cross tabulation of subjects with no progesterone exposure. These groups were then analyzed by the use of Somers' D. A significant relationship $(p=0.019)$ was found between results of cytology and histology samples for subjects with no progesterone exposure.

Table 4-5 notes results of the analysis between cytology and histology in the IUD group. Again, the data were collapsed as described above in Table 4-3. This group was then analyzed by the use of Somers' D. A significant relationship $(p=0.019)$ was found between results of cytology and histology samples for subjects using the progesterone IUD.

Table 4-6 notes results of the analysis between cytology and histology in the injection group. Again, the data were collapsed as described above in Table 4-3. This group was then analyzed by the use of Somers' D. No significance was found in the relationship ( $p=0.790)$ between results of cytology and histology samples for subjects using the progesterone injection.

Table 4-7 notes results of the analysis between cytology and histology for subjects with any progesterone exposure. Again, the data were collapsed as described above in Table 4-3. This group was then analyzed by the use of Somers' D. No significance was found in the relationship $(p=0.131)$ between results of cytology and histology samples for subjects with any progesterone exposure. 
Table 4-3. Crosstabulation of collapsed cytology and histology results for all cases $(n=180)$

\begin{tabular}{lccc}
\hline Histology result & \multicolumn{3}{c}{ Cytology result } \\
\cline { 2 - 4 } & $\begin{array}{c}\text { Low grade* } \\
(\mathrm{n}=117) \\
\mathrm{n}(\%)\end{array}$ & $\begin{array}{c}\text { High grade** } \\
(\mathrm{n}=63) \\
\mathrm{n}(\%)\end{array}$ & $\begin{array}{c}\text { Total } \\
(\mathrm{n}=180)\end{array}$ \\
\hline Negative & $43(36.8)$ & $20(31.7)$ & 63 \\
Low grade*** & $63(53.8)$ & $18(28.6)$ & 81 \\
High grade**** & $11(9.4)$ & $25(39.7)$ & 36 \\
Total & 117 & 63 & 180 \\
$\%$ of total & 65 & 35 & \\
\hline
\end{tabular}

Notes: Somers' D $p=0.008$.

*Low grade cytology includes ASCUS no HPV result, ASCUS HPV positive, ASCUS HPV negative, and LSIL.

**High grade cytology includes HSIL, AGC, ASCUS-H, and LSIL-H.

*** Low grade histology includes Cervicitis, CIN I.

**** High grade histology includes CIN II, CIN III, CIS, invasive neoplasia, adenocarcinoma. 
Table 4-4. Crosstabulation of collapsed cytology and histology results for no progesterone exposure $(n=72)$

\begin{tabular}{lccc}
\hline Histology result & \multicolumn{3}{c}{ Cytology result } \\
\cline { 2 - 4 } & $\begin{array}{c}\text { Low grade* } \\
(\mathrm{n}=47) \\
\mathrm{n}(\%)\end{array}$ & $\begin{array}{c}\text { High grade** } \\
(\mathrm{n}=25)\end{array}$ & $\begin{array}{c}\text { Total } \\
(\mathrm{n}=72) \\
\mathrm{n}(\%)\end{array}$ \\
\hline Negative & $19(40.4)$ & $7(28.0)$ & $26(36.1)$ \\
Low grade*** & $24(51.1)$ & $7(28.0)$ & $31(43.1)$ \\
High grade**** & $4(8.5)$ & $11(44.0)$ & $15(20.8)$ \\
Total & 47 & 25 & 72 \\
$\%$ of total & 65.3 & 34.7 & 100.0 \\
\hline
\end{tabular}

Notes: Somers' D $p=0.019$.

*Low grade cytology includes ASCUS no HPV result, ASCUS HPV positive, ASCUS HPV negative, and LSIL.

**High grade cytology includes HSIL, AGC, ASCUS-H, and LSIL-H.

*** Low grade histology includes Cervicitis, CIN I.

****High grade histology includes CIN II, CIN III, CIS, invasive neoplasia, adenocarcinoma. 
Table 4-5. Crosstabulation of collapsed cytology and histology results for progesterone IUD $(n=35)$

\begin{tabular}{lccc}
\hline Histology result & \multicolumn{3}{c}{ Cytology result } \\
\cline { 2 - 4 } & $\begin{array}{c}\text { Low grade* } \\
(\mathrm{n}=23) \\
\mathrm{n}(\%)\end{array}$ & $\begin{array}{c}\text { High grade** } \\
(\mathrm{n}=12)\end{array}$ & $\begin{array}{c}\text { Total } \\
(\mathrm{n}=35) \\
\mathrm{n}(\%)\end{array}$ \\
\hline Negative & $10(43.5)$ & $3(25.0)$ & $13(37.1)$ \\
Low grade*** & $13(56.5)$ & $3(25.0)$ & $16(45.7)$ \\
High grade**** & $0(0.0)$ & $6(50.0)$ & $6(17.1)$ \\
Total & 23 & 12 & 35 \\
$\%$ of total & 65.0 & 35.0 & 100.0 \\
\hline
\end{tabular}

Notes: Somers' D $p=0.019$.

*Low grade cytology includes ASCUS no HPV result, ASCUS HPV positive, ASCUS HPV negative, and LSIL.

**High grade cytology includes HSIL, AGC, ASCUS-H, and LSIL-H.

*** Low grade histology includes Cervicitis, CIN I.

****High grade histology includes CIN II, CIN III, CIS, invasive neoplasia, adenocarcinoma. 
Table 4-6. Crosstabulation of collapsed and histology results for progesterone injection $(n=73)$

\begin{tabular}{lccc}
\hline Histology result & \multicolumn{3}{c}{ Cytology result } \\
\cline { 2 - 4 } & $\begin{array}{c}\text { Low grade* } \\
(\mathrm{n}=47) \\
\mathrm{n}(\%)\end{array}$ & $\begin{array}{c}\text { High grade** } \\
(\mathrm{n}=26) \\
\mathrm{n}(\%)\end{array}$ & $\begin{array}{c}\text { Total } \\
(\mathrm{n}=73) \\
\mathrm{n}(\%)\end{array}$ \\
\hline Negative & $14(29.8)$ & $10(38.5)$ & $24(32.9)$ \\
Low grade*** & $26(55.3)$ & $8(30.8)$ & $34(46.6)$ \\
High grade**** & $7(14.9)$ & $8(30.8)$ & $15(20.5)$ \\
Total & 47 & 26 & 73 \\
$\%$ of total & 64.4 & 35.6 & 100.0 \\
\hline
\end{tabular}

Notes: Somers' D $p=0.790$.

*Low grade cytology includes ASCUS no HPV result, ASCUS HPV positive, ASCUS HPV negative, and LSIL.

**High grade cytology includes HSIL, AGC, ASCUS-H, and LSIL-H.

*** Low grade histology includes Cervicitis, CIN I.

$* * * *$ High grade histology includes CIN II, CIN III, CIS, invasive neoplasia, adenocarcinoma. 
Table 4-7. Crosstabulation of collapsed cytology and histology result for any progesterone exposure $(n=108)$

\begin{tabular}{lccc}
\hline Histology result & \multicolumn{3}{c}{ Cytology result } \\
\cline { 2 - 4 } & $\begin{array}{c}\text { Low grade* } \\
(\mathrm{n}=78) \\
\mathrm{n}(\%)\end{array}$ & $\begin{array}{c}\text { High grade** } \\
(\mathrm{n}=30)\end{array}$ & $\begin{array}{c}\text { Total } \\
(\mathrm{n}=108) \\
\mathrm{n}(\%)\end{array}$ \\
\hline Negative & $24(34.3)$ & $13(34.2)$ & $37(34.3)$ \\
Low grade*** & $39(55.7)$ & $11(28.9)$ & $50(46.3)$ \\
High grade**** & $7(10.0)$ & $14(36.8)$ & $21(19.4)$ \\
Total & 78 & 30 & 108 \\
$\%$ of total & 64.8 & 35.2 & 100.0 \\
\hline
\end{tabular}

Notes: Somers' D $p=0.131$.

*Low grade cytology includes ASCUS no HPV result, ASCUS HPV positive, ASCUS HPV negative, and LSIL.

**High grade cytology includes HSIL, AGC, ASCUS-H, and LSIL-H.

*** Low grade histology includes Cervicitis, CIN I.

**** High grade histology includes CIN II, CIN III, CIS, invasive neoplasia, adenocarcinoma. 


\section{Research Question 3: Is There a Difference in the Relationship between Cytology and Histology in Four Groups of Women with Abnormal Cytology Results?}

Table 4-8 reports agreement between cytology and histology results by progesterone exposure. Chi square analysis was performed $\chi^{2}(2, \mathrm{n}=180)=0.5$, $\rho=0.781$. No difference in the association between cytology and histology by progesterone exposure was noted.

Table 4-9 breaks down the disagreement rates further into the finer levels of either false positive or false negative effect. A false positive effect (defined as the cytology result overestimating the severity of the cervical cells when judged against histology results) was noted among $52.8 \%$ of the non-hormonal/no contraception group, $51.4 \%$ of the progesterone IUD group, $47.9 \%$ of the progesterone injection group, and $49.1 \%$ of the group combining the two progesterone methods. A false negative effect (defined as the histology result being more severe than the cytology result) was noted in $5.6 \%$ of the non-hormonal/no contraception group, none of the IUD group, $9.6 \%$ of the injection group, and $6.5 \%$ when the two progesterone method groups were combined. A false negative effect was rare at less than $10 \%$ for any of the categories. No significant association between type of progesterone exposure and level of agreement (agree, false negative, false positive) was noted $(p=0.83) ; \chi^{2}(1, \mathrm{n}=180)=.05$.

The association between cytology and histology results was tested by the use of Chi Square statistics. Table 4-10 shows no difference in association between cytology to histology results by progesterone exposure (none, IUD or injection) $(p=0.781) ; \chi^{2}(2$, $\mathrm{N}=180)=0.5$. Table 4-10 also shows no difference in association by level of agreement (either agree/disagree) between cytology to histology $(p=0.83)$ by either any progesterone exposure as compared to none, with $\chi^{2}(1, \mathrm{~N}=180)=.05$. No difference in association between cytology and histology was noted $(p=0.396) ; \chi^{2}(4, \mathrm{~N}=180)=4$ after breaking down the disagreement level into two sub-levels of disagreement (false positive or false negative) by progesterone exposure per group (IUD, injection, or none). Finally, no difference in association between cytology and histology was noted when analyzing degree of agreement between cytology and histology by sub-levels of false negative or false positive, by any progesterone exposure (IUD or injection) versus no progesterone exposure $(p=0.88) ; \chi^{2}(2, \mathrm{~N}=180)=0.26$.

\section{Research Question 4: Is There a Difference in the Relationship between Cytology and Histology, by Length of Time Using Either Depot Medroxyprogesterone Acetate or Progesterone IUD?}

Two logistic regressions were undertaken to address this question in which the variables length of time using progesterone, age, group (whether IUD or injection), and group by time using progesterone were analyzed for interaction. The logistic regression model, roughly analogous to the multiple linear regression, allows for analysis with dichotomous variables. The logistic regression models allowed for testing whether there was a relationship between time on progesterone and the relationship between cytology and histology. The first regression model analyzed progesterone in the context of agree 
Table 4-8. Agreement between cytology and histology results by progesterone exposure

\begin{tabular}{lccccc}
\hline Agreement & $\begin{array}{c}\text { Non-hormonal or } \\
\text { no contraception } \\
(\mathbf{n}=\mathbf{7 2}) \\
\mathbf{n}(\mathbf{\%})\end{array}$ & $\begin{array}{c}\text { Progesterone } \\
\text { IUD } \\
(\mathbf{n}=\mathbf{3 5}) \\
\mathbf{n}(\mathbf{\%})\end{array}$ & $\begin{array}{c}\text { Progesterone } \\
\text { injection } \\
(\mathbf{n}=\mathbf{7 3}) \\
\mathbf{n}(\mathbf{\%})\end{array}$ & $\begin{array}{c}\text { Combined IUD } \\
\text { and injection } \\
(\mathbf{n}=\mathbf{1 0 8}) \\
\mathbf{n}(\mathbf{\%})\end{array}$ & $\begin{array}{c}\text { Total } \\
(\mathbf{n}=\mathbf{1 8 0}) \\
\mathbf{n}(\mathbf{\%})\end{array}$ \\
\hline Agree & $30(41.7)$ & $17(48.6)$ & $31(42.5)$ & $48(44.4)$ & $78(43.3)$ \\
$\begin{array}{l}\text { Any } \\
\text { disagreement }\end{array}$ & $42(58.3)$ & $18(51.4)$ & $42(57.5)$ & $60(55.6)$ & $102(56.7)$ \\
Total & $72(100)$ & $35(100)$ & $73(100)$ & $108(100)$ & $180(100)$ \\
\hline
\end{tabular}

Notes: $\chi^{2}(2, \mathrm{n}=180)=0.5, \rho=0.781$. 
Table 4-9. Agree, false negative, or false positive results between cytology and histology by progesterone exposure

\begin{tabular}{lccccc}
\hline Agreement & $\begin{array}{c}\text { Non-hormonal or } \\
\text { no contraception } \\
(\mathbf{n}=\mathbf{7 2}) \\
\mathbf{n}(\mathbf{\%})\end{array}$ & $\begin{array}{c}\text { Progesterone } \\
\text { IUD } \\
(\mathbf{n}=\mathbf{3 5}) \\
\mathbf{n}(\mathbf{\%})\end{array}$ & $\begin{array}{c}\text { Progesterone } \\
\text { injection } \\
(\mathbf{n}=\mathbf{7 3}) \\
\mathbf{n}(\mathbf{\%})\end{array}$ & $\begin{array}{c}\text { Combined IUD } \\
\text { and injection } \\
(\mathbf{n}=\mathbf{1 0 8}) \\
\mathbf{n}(\mathbf{\%})\end{array}$ & $\begin{array}{c}\text { Total } \\
(\mathbf{n}=\mathbf{1 8 0}) \\
\mathbf{n}(\mathbf{\%})\end{array}$ \\
\hline Agree & $30(41.7)$ & $17(48.6)$ & $31(42.5)$ & $48(44.4)$ & $78(43.3)$ \\
False positive & $38(52.8)$ & $18(51.4)$ & $35(47.9)$ & $53(49.1)$ & $91(50.6)$ \\
$\begin{array}{l}\text { False } \\
\text { negative }\end{array}$ & $4(5.6)$ & $0(0.0)$ & $7(9.6)$ & $7(6.5)$ & $11(6.1)$ \\
Total & $72(100)$ & $35(100)$ & $73(100)$ & $108(100)$ & $180(100)$ \\
\hline
\end{tabular}

Note: $\chi^{2}(1, \mathrm{n}=180)=.05$. 
Table 4-10. Tests of the cytology/histology relationship and progesterone exposure

\begin{tabular}{|c|c|c|c|}
\hline $\begin{array}{l}\text { Table structure and variable } \\
\text { encoding }\end{array}$ & $\begin{array}{l}\text { Chi-square } \\
\text { (df) }\end{array}$ & $\rho$-value & $\begin{array}{l}\text { Bonferroni-adjusted multiple } \\
\text { comparisons of agreement/concordance } \\
\text { rates between progesterone groups* }\end{array}$ \\
\hline $\begin{array}{l}\text { Cytology/histology agreement (agree, } \\
\text { disagree) by progesterone exposure } \\
\text { (none, IUD, injection) }\end{array}$ & $\begin{array}{l}0.495 \\
(2)\end{array}$ & 0.781 & (None significant) \\
\hline $\begin{array}{l}\text { Cytology/histology agreement (agree, } \\
\text { disagree) by progesterone exposure } \\
\text { (any [IUD or injection], none) }\end{array}$ & $\begin{array}{c}0.046 \\
(1)\end{array}$ & 0.830 & (None significant) \\
\hline $\begin{array}{l}\text { Cytology/histology agreement (agree, } \\
\text { false positive, false negative) by } \\
\text { progesterone exposure (none, IUD, } \\
\text { injection) }\end{array}$ & $\begin{array}{l}4.075 \\
(4)\end{array}$ & 0.396 & (None significant) \\
\hline $\begin{array}{l}\text { Cytology/histology agreement (agree, } \\
\text { false positive, false negative) by } \\
\text { progesterone exposure (any [IUD or } \\
\text { injection], none) }\end{array}$ & $\begin{array}{l}0.255 \\
(2)\end{array}$ & 0.880 & (None significant) \\
\hline
\end{tabular}

Notes: $\chi^{2}(2, \mathrm{~N}=180)=0.5$.

*Are only relevant if the Chi-Square test is statistically significant. 
(yes/no), and the second in the context of false positive (yes/no). In the omnibus test of the first model, $\chi^{2}(4, \mathrm{n}=108)=4.95, p=0.29$. The omnibus test of the second model noted $\chi^{2}(4, \mathrm{n}=108)=4.08, p=0.40$. No relationship between time of progesterone exposure and accuracy of cytologic interpretation was noted, which is congruent with the finding that there was no difference in relationship between the groups regardless of progesterone exposure or type.

\section{Post Hoc Power Analyses}

A post hoc power analysis was run to determine the power in the study. The analyses were based on observed effect sizes, and were run on each of the four Chi square analyses with criterion set at .05 (two tailed) test. Results are shown in Table 4-11. The effect size for the first Chi square analysis was .05. With the sample size of 180 the study will have power of $9 \%$ to yield a statistically significant result. Total number of cases to detect an effect of this size with $80 \%$ power at the .05 alpha level would be 3,542 .

Power analysis on the second Chi square analysis revealed an effect size of .02. With the sample size of 180 the study will have power of $6 \%$ to yield a statistically significant result. Total number of cases to detect an effect of this size with $80 \%$ power at the .05 alpha level would be 20,062 .

Power analysis on the third Chi square analysis revealed an effect size of .16. With the sample size of 180 the study will have power of $36 \%$ to yield a statistically significant result. Total number of cases to detect an effect of this size with $80 \%$ power at the .05 alpha level would be 471 .

Power analysis on the fourth Chi square analysis revealed an effect size of .05 . With the sample size of 180 the study will have power of $9 \%$ to yield a statistically significant result. Total number of cases to detect an effect of this size with $80 \%$ power at the .05 alpha level would be 3,809 . 
Table 4-11. Post hoc power analyses

\begin{tabular}{lccc}
\hline Model & $\begin{array}{c}\text { Observed } \\
\text { effect size }\end{array}$ & $\begin{array}{c}\text { Power to yield } \\
\text { stat. sig. result \% }\end{array}$ & $\begin{array}{c}\text { Total number of cases } \\
\text { to detect effect }\end{array}$ \\
\hline 1st & .05 & 9 & 3,542 \\
2nd & .02 & 6 & 20,062 \\
3rd & .16 & 36 & 471 \\
4th & .05 & 9 & 3,809 \\
\hline
\end{tabular}




\section{CHAPTER 5. DISCUSSION}

The purpose of this study was to examine the accuracy of cervical cytologic findings in women who were using either one of two forms of progesterone only contraception, depot medroxyprogesterone acetate injection or the progesterone IUD, as compared to women who either used a non-hormonal form of contraception or no contraception at all. This section will first review the relationship between factors such as race and socioeconomic status on a woman's decision to use one of the progesterone methods studied. Next, an exploration into the study population characteristics (smoking status, marital status, obstetrical history) is undertaken. Third, the relationship between cytology and histology according to progesterone exposure, and then the differences in that relationship, are explored. Last, significance of the findings, study limitations, and conclusions are discussed.

\section{Use of Contraception Method}

There was a higher percentage of black subjects (64\%) compared to white subjects (28.8) who used the progesterone injection. This finding is consistent with other studies showing that $84 \%$ of progesterone injection users are black. ${ }^{34,35,90}$ A greater percentage of white subjects $(54.3 \%)$ than black subjects $(28.6 \%)$ used the progesterone IUD. Socioeconomic status was not obtained in this study.

A patient's race/ethnicity and socioeconomic status have been shown to be factors in a practitioner's decision of recommendation for type of contraception, ${ }^{35}$ which may account for why more white women than black women were using intrauterine contraception. Dehlendorf et al. (2010) ${ }^{35}$ noted in their study on provider recommendations for intrauterine contraception that white women of low socioeconomic status were significantly less likely than white women of high socioeconomic status to have intrauterine contraception recommended to them by their providers. Race did not have bearing on provider recommendation among women of high socioeconomic status. A 2007 study noted 74\% of progesterone injection users were of low socioeconomic status. ${ }^{90}$ Progesterone injections are far less costly at the point of service than intrauterine devices at initiation ( $\$ 35-\$ 75$ average cost per injection versus $\$ 500$ to $\$ 1000$ at the time of insertion for IUD). ${ }^{92}$ Cost at initiation may underscore the rationale why women of lower socioeconomic means actually choose the progesterone injection. Providers may not offer the IUD to women of lower socioeconomic means because there is an assumption that it would be unaffordable for them. However, IUD device and insertion costs are generally covered equally as well as the progesterone contraceptive injection, so why this thought exists cannot be thoroughly explained. The aspect of economic status and effect on provider recommendation for contraception was not explored in this study. Age has also been shown to have bearing on usage of progesterone injection as $33 \%$ of progesterone injection users are noted to be under the age of $19 .^{34}$ 


\section{Smoking Status}

The total sample had higher smoking rates than would be observed in a random sample population. The percentage of smokers in the study sample (30.6\%) was higher than that noted in the general population of females in the geographical area in Tennessee $(23.7 \%)^{27}$ The smoking statistic for women in general in Tennessee is higher than the percentage of smokers noted in the non-hormonal/no contraceptive use group $(22 \%)$, but lower than the rates noted for the IUD users (25.7\%), the injection users $(41.1 \%)$, the combined injection or IUD group (36.1\%), or the overall smoking rate $(30.6 \%)$ which included all subjects. The study subjects were located in the geographic area of Middle Tennessee, where the most current reported smoking statistics noted a $25.3 \%$ smoking prevalence among whites, and a $23.9 \%$ prevalence among blacks (statistics included both men and women). Black females living in Tennessee have been noted to have the lowest prevalence of smoking, at $19.5 \% .{ }^{27}$ The rates for smoking among the study subjects were highest in the progesterone injection group (41.1\%) and lowest in the non-hormonal/non contraceptive group $(22.2 \%)$.

The finding that there was a higher percentage of smokers among the progesterone injection group is not consistent with established findings on either race, or adolescence and smoking. Current information on trends in smoking across races in adult women ${ }^{107}$ show the highest prevalence rate of smoking among American Indian women (22.4\%) followed by whites (20.6\%), then blacks (17.8\%), Hispanic (10.7\%) and Asians (4.7\%). The fact that the progesterone injection group contained more smokers was unexpected, given that the progesterone group was comprised largely of black women. There is not an obvious explanation for this difference, and is therefore an issue for further investigation. The progesterone injection group may have contained more adolescents and young adults than the other two groups. Davis, Nonnemaker, Asfaw, and Vallone (2010) ${ }^{108}$ reported on both perceived and actual smoking rates among adolescents in the U.S. The perception among study subjects was that American Indian adolescents had the highest smoking rates $(48.4 \%)$ followed by black adolescent females (46.6\%), followed by Hispanic (44.2\%), than white (37.4\%), then Asian (32.4\%) adolescents. However, the actual smoking rates among adolescents were quite different at $15.8 \%$ for American Indian adolescents, followed by $10.5 \%$ of white adolescents, $9.6 \%$ of Hispanic adolescents, $6.2 \%$ of black adolescents, and lastly, 5.4\% of Asian adolescents. Two other studies have demonstrated that black adolescents are less likely to smoke than white adolescents. ${ }^{109,110}$ Data suggest, however, that this pattern is altered in late adolescence and early adulthood in that black adults have a higher smoking prevalence rate when compared with other racial/ethnic groups.

The variations may be the result of differences in socioeconomic determinants (e.g. marital status, education, and race/ethnicity) of smoking, as well as differing social norms regarding tobacco use in the geographic area where the study was conducted. Socioeconomic status was not collected for the purposes of this study. Numerous studies have confirmed that socioeconomic factors have an influence on smoking prevalence. Adult smoking prevalence is greater among those of lower socioeconomic status. ${ }^{111-113}$ Socioeconomic status was not collected for the purposes of this study, yet Davidson 
county, which encompasses the largest area where the subjects resided, has $17.1 \%$ of residents living below poverty level, with a mean income of $\$ 46,249 .^{26}$ (U.S. Census Bureau, 2011). The Tennessee Department of Public Health reported that prevalence of smoking was lowest among those earning $\$ 75,000$ or more (at $13.3 \%$ ), and highest among those whose household incomes were less than $\$ 25,000$ annually (at 35.8\%). ${ }^{27}$

Numerous papers have documented the enhanced mutagenic effect of HPV infected cervical cells exposed to smoking, whether by primary or second hand smoking exposure. ${ }^{8,9,25,28,47,48,114-118}$ Elevated tobacco and nicotine by-products, specifically cotinine, concentrate in cervical mucus and accelerate the progression rate of developing squamous intraepithelial dysplasia and neoplasia. The process of DNA damage attributable to the tobacco product and by products is directly caused by the interruption of p53 and pRb gene paths via the over expression of the E6 and E7 viral oncogenes. ${ }^{53}$ Nicotine levels in the cervical mucus of female smokers with cervical intraepithelial neoplasia have been noted to be 40 fold that of serum levels. ${ }^{50}$

Smoking may enhance development of cervical dysplasia via weakening of the immune system. The HPV infection is allowed to persist within the cells, leading to dysplasia and neoplasia in someone with less than optimal immune system protection to clear the virus. ${ }^{114,119}$ Langerhans' cells, with their macrophage like behavior, have been noted to be present in far less concentration in the cervical epithelium of female smokers. ${ }^{120}$ Smoking has an accelerator effect on both cellular metaplasia, and mitosis. ${ }^{8}$

Existing information regarding the effect of smoking on HPV infected cervical cells supports the finding of higher frequency rates of smoking among those women in this study. The positive association between smoking and cervical dysplasia underscores the greater incidence of smokers among the subjects in this study. By comparison, similar rates of tobacco use have been noted among study subjects in similar studies. Tobacco usage rate reported among premenopausal study subjects by Moore et al. was $49 \%$, and $36 \%$ among menopausal women, in their study of 359 women presenting to the colposcopy clinic. ${ }^{39}$ Coker et al. (2002) ${ }^{121}$ reported the following smoking rates among women with HSIL cytology results: $36 \%$ reported that they had ever smoked, with $31 \%$ currently smoking and 5\% former smokers. Women with LSIL Pap results reported having ever smoked $34 \%$ of the time, while $24 \%$ currently smoked, and $9 \%$ were former smokers. ${ }^{121}$

Moscicki et al. (2008) ${ }^{122}$ reported the following smoking rates among their study sample of adolescents and young women: $27.4 \%$ of those with CIN I or less were current smokers, $30.9 \%$ of those with CIN 2 were current smokers, and $36.6 \%$ of those with CIN 3 were current smokers. ${ }^{122}$ Women with minimally abnormal cytology results $(\mathrm{N}=$ 5,060 ) had a $35 \%$ current smoking status prevalence, and a $12 \%$ former smoking status prevalence. ${ }^{80}$ A population based case control study conducted in Spain and Columbia noted smoking rates consistent with those in studies conducted in the US. Bosch et al. $(1992)^{87}$ noted among their study population, that $26.4 \%$ in Spain, and $50.5 \%$ in Columbia had ever smoked (encompassing former and current smokers), while only $16.8 \%$ of the control group in Spain had smoked, and $40 \%$ of the Columbian control group had ever smoked. ${ }^{87}$ 
Another reason that the smoking rates could have been higher in this sample was the fact that female smokers are less likely to seek out regular cervical neoplasia screening. ${ }^{57,58,69}$ Dysplasia may be detected earlier, and if necessary, treated, with regular cervical neoplasia screening, which would result in subsequent cytology findings returning as normal. Time from prior screening to collection of abnormal Pap result was not collected on the subjects in this study. Future research should include this variable since delaying screening would allow time for cervical cells to continue to change and move to a high enough level of abnormality to be present in the cytological result.

\section{Marital Status}

The largest percentage of married women was in the IUD group, and the lowest percentage of married women was in the progesterone injection group. Clinical recommendations regarding appropriate IUD candidate selection excluded women who were not in a mutually monogamous relationship, until very recently, which could largely explain the greater number of married women who had the IUDs in situ. ${ }^{123}$ Only very recently have recommendations changed to allow inclusion of women who have multiple partners to be candidates for IUD placement. ${ }^{94}$ The pattern of use noted in this study group does correspond with the pattern of IUD use noted in the general population. ${ }^{94}$

\section{Obstetrical History}

The progesterone injection group contained the largest percentage of nulligravid women $(16.4 \%)$ and the IUD group contained the lowest percentage of nulligravid subjects $(11.4 \%)$. This is consistent with practice trends. ${ }^{124}$ Nulligravid women have only recently begun to be included as appropriate candidates for IUD placement. Historically IUDs were not inserted into a nulligravid woman because of the theoretical increased risk between pelvic inflammatory disease (PID) and IUD use. The widespread thought has been that there was an increased risk of PID among IUD users, and PID is a risk factor for female infertility. Thus, practitioners did not place IUDs in nulligravid women. ${ }^{124}$ The link between PID and IUD use has been clarified and nulligravid women have been deemed appropriate candidates for IUD placement. ${ }^{91}$ There will be a lag period of time before that paradigm shift is reflected in statistics demonstrating IUD usage by gravida/parity, because of the lag in time between change in recommendation, and actual observation of that change in clinical practice,

\section{Observed Frequency of Abnormal Pap Results}

Frequency of the various cytologic abnormalities was similar across the groups. The prevalence of HSIL cytology results was greater among the study population (23.3\%) as compared to what has been observed in other studies. Clark et al. (2011) noted the following prevalence of abnormalities in their study, in order from most to least prevalent: LSIL (44.4\%), ASCUS, which included all designations of ASCUS (38.7\%), HSIL $(8.6 \%)$ and AGC $(8.6 \%) .{ }^{36}$ Hoekstra et al. $(2006)^{104}$ noted the following breakdown 
of cytology classification abnormality in their study: ASCUS, which included all designations of ASCUS (12.8\%), LSIL (9\%), HSIL (6\%), AGC (1\%). ${ }^{104}$ Variation in prevalence of type of cytology may vary by risk factors of participant groups in various studies, as well as inclusion of pregnant or menopausal women (both were excluded from this study). Inclusion of post-menopausal women, representing a hypoestrogenic state, and pregnant women, representing a hyperestrogenic state, could affect the observed frequency of the various reported abnormalities.

\section{Relationship between Cytology and Histology According to Progesterone Exposure}

There was a significant relationship between cytology and histology overall $(p=.008)$. This confirms what is well known about the cytology/histology relationship. Specifically, multiple studies have noted the strong positive association between cytologic screening and histologic diagnosis in detecting cervical dysplasia. ${ }^{13,14,125}$

There was a significant association between cytology and histology $(p=.019)$ among women who had no progesterone exposure (Table 4-3). This again would be expected, based on what is known in the literature. There was a significant association between cytology and histology among women using the progesterone IUD $(p=.019)$ (Table 4-4). This again is consistent with what exists in the literature regarding cytologic and histologic association.

There was not a significant association between cytology and histology findings among progesterone injection users $(p=.790)$ (Table 4-5). This finding is not consistent with the prior analyses in this study of no progesterone exposed subjects, IUD users and the entire study group overall. However, these initial analyses are subgroup analyses which use only the low grade/high grade concept of defining the cytology/histology relationship. Analysis using only the low grade/high grade concept does not address the nuances in the cytology/histology relationship of those false negative and false positive situations which occur within the realm of the low grade/high grade relationships. The more precise approach to agreement used in further analysis clarifies to a greater degree, this question of agreement noted in this analysis. This analysis result is important, however, because it provides the impetus to look further into the relationship between cytology and histology in women using the progesterone injection for contraception, particularly because this relationship differs from the relationship between cytology and histology noted between women not exposed to any exogenous hormones.

No significant relationship between cytology and histology findings was found among subjects with any progesterone exposure (whether IUD or injection) $(p=.131)$ (Table 4-6). This finding is not consistent with those analyses run on the entire study population, any progesterone exposure groups, and the IUD group. When only the low grade/high grade concept of defining the cytology/histology relationship is used, there is room for error in overlooking the false negative and false positive findings that occur within the various cytology/histology relationships. 
Prior studies examining the effect of progesterone only contraception on the cytologic/histologic relationship did not provide a defining outcome variable, as was provided in this study. The ability to determine not only agreement/disagreement, but the level of that disagreement, captures those subtleties in the relationship between cytology and histology that would be lost if the level of disagreement was not defined. The conclusion that cytologic interpretation is affected by progesterone exposure could be drawn if analysis ceased at the level of agree/disagree. The new defining outcome variable enables a deeper level of analysis where the issue can be more discreetly defined.

Chi square analysis of the relationships between cytology and histology for any progesterone exposure (which would be the combined groups of the IUD and the injection) noted a non-significant association between cytology and histology $(p=0.13)$ (Table 4-7). Subgroup analyses that use only the low grade/high grade concept, because they do not address the subtleties the groups, may miss the between false negative and false positive situations which occur within the low grade/high grade realm of possible cytology/histology combinations.

\section{Difference in Relationship between Cytology and Histology According to Progesterone Exposure}

The first Chi square analysis was done to address the question, whether the cytology/histology relationship could be classified as an agree situation (either yes or no) across each of the groups individually (the non-hormonal/no contraception group, the IUD group, and the injection group). The rates of agree, either yes or no, were very similar across groups. There was no significant association between progesterone exposure by type and level of agreement by the two levels of either agree/disagree $(p=.781)$. The second analysis done to address this question grouped the two progesterone exposed groups together. The purpose of this analysis was to evaluate the relationship of cytology to histology by either no progesterone exposure (the nonhormonal/con contraception use group) or any progesterone exposure (the IUD and injection groups together). The percent of agreement, either yes or no, is very close between the progesterone and non-progesterone exposed groups. There was no difference in association between cytology and histology $(p=0.83)$ in this second analysis, by either any progesterone exposure (i.e. IUD and injection groups combined) or no progesterone exposure.

The level of agreement was broken down further in the third analysis run to address this question, Each group was analyzed by progesterone exposure (either none, IUD or injection) in this analysis by either agree, or if no, then whether false negative or false positive. Of note, a false negative relationship was noted very rarely, at less than $10 \%$ for any of the groups. The finding that a false negative relationship was noted rarely is reassuring, in that the incidence of cytologic screenings underestimating clinical situations wherein women have a much greater degree of pathology is extremely low. No significant association was found $(p=0.83)$ between type of progesterone exposure and agreement by the levels of agree, false negative, or false positive. 
The level of agreement used was the agree, false negative or false positive, newly defined outcome variable in the fourth and final analysis run to address this question. The analysis examined the relationship of cytology to histology by either any progesterone exposure (the IUD and injection groups combined), or no progesterone exposure (the non-hormonal or no contraception group). No significant difference in association between cytology and histology was found $(p=0.88)$ by any progesterone exposure.. There was no significant difference in association between cytology and histology by progesterone exposure, nor significant difference in agreement between cytology and histology by progesterone exposure.

The findings in this study are congruent with the findings of Zhu \& Wilbur (1998), ${ }^{100}$ who noted no significant increase in the rate of ASCUS preceeded squamous intraepithelial lesions among progesterone users. The study findings are also consistent with those of Hoekstra et al (2006), who noted that the rate of false-positive cytologic screening results was not different among hormone exposed women (either the progesterone injection, progesterone implant, or combined oral contraception) as compared to non hormone exposed women. ${ }^{104}$ These study findings are also congruent with those of Darwish et al. (2004), who noted no increase in abnormal cytologic results among progesterone contraception users. ${ }^{103}$ Most recently, Clark et al. (2011), also noted similar findings in their study of false-positive 1 cervical cytology results among women using either progesterone only or combined contraception. ${ }^{36}$

\section{Relationship between Cytology and Histology, by Length of Time Using either Depot Medroxyprogesterone Acetate or Progesterone IUD}

Two logistic regressions were undertaken in which the variables of time on progesterone, age, group (IUD or injection), and group by time on progesterone were analyzed for interaction. The outcome in logistic regression is dichotomous (agree or disagree) (false positive or not false positive). The logistic regression models allowed a test of (after adjusting for age) whether there was a relationship between time on progesterone and the type of progesterone delivery system on the dichotomous outcome. The two regressions demonstrated that the models for either regression were not stellar (by Omnibus test of model coefficients). No relationship between time of progesterone exposure and accuracy of cytologic interpretation was noted, which is congruent with the finding that there was no difference in relationship between the groups regardless of progesterone exposure or type.

The first analysis examined the relationship between cytology and histology in the context of agree (yes or no). Model 1 was designed to test the effect of time on progesterone and mode of progesterone delivery on the likelihood of agreement between cytology and histology findings controlling for age. Additionally, an interaction term of time by progesterone delivery mode was included to test whether there was a difference in the relationship between the length of progesterone exposure and the likelihood of agreement on the basis of either progesterone mode of delivery. An investigation on the variable of time on a non- significant relationship may not have been necessary. 
The effect of duration of exposure to progesterone was not significant ( $p=$ 0.107). There was no evidence of an association between duration of progesterone exposure and the likelihood of a false positive finding. Both of these regressions supported the findings from the analysis of research questions 2 and 3, which demonstrated that progesterone exposure was not associated with a difference in the proportions of patients having agreement, false negative or false positive findings.

\section{Significance of Findings}

Although our exploratory study was significantly underpowered, findings suggest that the subjects in this study who used either the progesterone IUD or injection had no difference in association of their cytology to histology findings compared to women who had no progesterone exposure and further study is needed to confirm these results. Also there is a greater degree of prevalence of smoking among the women in the study with abnormal cytology results, as compared to the smoking rates among the general population. Research should continue to be aimed at investigation of the additive effect of smoking on dysplasia rates in women infected with HPV.

Areas for future research include analyzing other disease processes in women who both smoke and use progesterone only contraception. Investigating whether there are differences in morbidity and mortality rates for progesterone exposed women who have chronic diseases such as osteoporosis and coronary artery disease has been understudied. Also, since coronary artery disease remains the primary cause of mortality in women ${ }^{126,127}$ investigation of any exogenous hormonal association to coronary artery disease is an important research topic. Further investigation into the aspects of morbidity and mortality associated with acute myocardial effects in women exposed to progesterone is a focused area of cardiac health research that necessitates further research.

This study analyzed two forms of progesterone only contraception, but there are multiple other forms of progesterone that have not been studied to determine if there is an effect on the relationship between cytology and histology. Oral progesterone only pills and implantable forms of progesterone, such as the relatively new implantable mode, etonogestrel subdermal implant (Implanon $\left.{ }^{\circledR}\right)$, are two forms that have not been evaluated critically for any effect on cervical cells. The delivery mode of progesterone in this study was either systemic (the injection) or local (the IUD). Other delivery modes may have varying effects on cervical cells, and thus may affect cytological interpretation accuracy differently than those modes included in this study.

Another important issue related to research in this area is that the prevalence of various high risk HPV types varies among populations and countries. ${ }^{5,81}$ Repeating this study among populations with different high risk HPV type prevalence may reveal associations not detected in this study. Also, analyzing for effect difference among varying population groups would be of value. The proportion of Hispanic and Asian subjects in this study was small. Repeating the study among those particular populations may reveal additional information not detected in the current study. Lastly, the progesterone IUD is used more widely in Europe than in North America (1-2\% in the 
U.S. versus as high as $24 \%$ in some European countries). ${ }^{124}$ Repeating the study in a geographic area with a higher progesterone IUD usage rate would likely yield a larger sample of IUD users than was obtained in this study.

\section{Limitations}

A primary limitation of this study was that there was a threat to the internal validity. The inability to control for either the same practitioners collecting the samples, or the same pathology professionals interpreting the samples could be seen as a limitation. The study undertook the examination of existing cytologic and histologic reports contained within the subjects' records. There was no way to assure that all the various practitioners or pathology professionals followed exactly the same standard as they provided their clinical services.

Another limitation of the study involved the use of an electronic database used for the data. Data, particularly demographic data, may have been missing from patient records. In addition, patient records are heavily reliant on the information first being correctly entered by patient care providers. However, this large database was an ideal medium to use for this particular study because of both the volume and heterogeneity of the subjects.

A limitation of the study was that a much larger sample size would be necessary to be able to draw conclusions from this study because of the lack of power that was calculated after the data analysis. Only $2 \%$ of US women use IUD devices, ${ }^{128}$ and a portion of those will have used the copper IUD rather than the progesterone IUD. The progesterone IUD subjects were anticipated to constitute the smallest number of subjects. One suggestion for future research would be replicating the study in a country outside of the US where the progesterone IUD has much wider usage. Further, the study subjects were all residents of one geographical urban area, with very few subjects from some racial groups, particularly Latino and Asian women.

\section{Conclusion}

Accuracy of cytologic interpretation is necessary for the appropriate treatment of women with cellular dysplasia or neoplasia. Factors which ostensibly could alter the accuracy of cytologic interpretation need to be identified and explored. Investigating factors which have potential to affect cytologic interpretation is important because of the potential for adverse physical and psychological affects in women given abnormal cytology results. Inaccurate results also lead to unnecessary follow up procedures and unnecessary costs. Exogenous progesterone affects cervical cellular characteristics, though the result of this effect on the accuracy of cervical cytologic interpretation is less clear. Little research has been conducted on whether the cellular changes related to progesterone alter the accuracy of cytological interpretation, and what has been done to date has had incongruent findings. Conducting this type of research study on progesterone contraceptive exposure and potential cervical cytologic changes is 
challenging for many reasons. First, a retrospective study design is the most feasible to use because only subjects with abnormal cytology test results are included. Second, obtaining a sample set of subjects who have an abnormal cytology result, with subsequent biopsy result and who also use a progesterone IUD is difficult because the usage rate of the progesterone IUD is lower in the U.S. than it is in many other countries. However, even considering the difficulties of conducting this type of study, the accuracy of cytologic interpretation is necessary to the appropriate treatment of women who have cellular dysplasia or neoplasia.

No significant association was found between progesterone contraception exposure and difference in accuracy of cytologic interpretation as compared to women with no progesterone contraception exposure. Additionally, no effect was noted between time of progesterone exposure and difference in agreement between cytology and histology. This study was the first to analyze the effect of the progesterone IUD versus the progesterone injection on the cytology/histology interpretation relationship. Comparison between IUD and progesterone injection was important because of the difference in delivery of the hormone (local with the IUD versus systemic with the injection).

This study was underpowered, but there is potential for conducting a similar study. The challenge would be in recruiting enough subjects to achieve power. A future study would very likely have to be a multi-center, multi-site study in order to recruit enough subjects with abnormal cytology results and who also used progesterone only contraception. Including countries outside of the U.S. would also very likely need to be considered, and would give a much richer sample. The recruiting of subjects from international sites who use varying types of contraception, and have varying sexual behavior patterns is a recommendation for future research.

Another recommendation for future research is to look into the various evaluation systems with which cells are interpreted by pathology professionals, and how those scales affect cellular interpretation. Studies included in this review of literature used varied methods of gradation in evaluating the maturation of cells. The use of different measurement scales may lead to some inconsistency across studies in both interpretation and evaluation of interpretation rates. Lastly, alternate forms of progesterone (implant and oral progesterone formulation) may also have varying effect on this phenomenon. Future studies could examine some of the other forms of progesterone to determine if the delivery system of progesterone has any effect on cervical cytology interpretation.

Cervical cytologic screening is the most efficacious way of detecting cervical neoplasia currently available. Any factor that could interfere with the accuracy of cytologic interpretation should be identified. Women at risk for cervical neoplasia should be made aware of any effects that exogenous hormones may have on the accuracy of cytologic interpretation, so that they can make informed choices regarding their contraception methods. Though this study did not reveal a relationship between either of the two forms of progesterone and interpretation differences when compared to nonprogesterone users, the results have limited utility due to small sample size and inadequate power. What can be derived from the study is a basis for comparing varied 
progesterone delivery systems, as well as format for repetition of a similar study in a multi center, multi site study. 


\section{LIST OF REFERENCES}

1. Moodley J. Combined oral contraceptives and cervical cancer. Curr Opin Obstet Gynecol. 2004;16:27-29.

2. Long HJ, Laack NN, Gostout BS. Prevention, diagnosis, and treatment of cervical cancer. Mayo Clin Proc. 2007;82(2):1566-1574.

3. Nanda K, McCrory DC, Myers ER, et al. Accuracy of the Papanicolaou test in screening for and follow-up of cervical cytologic abnormalities: A systematic review. Ann Intern Med. 2000;132(10):810-819.

4. Bosch FX, Lorincz A, Munoz N, Meijer CJ, Shah KV. The causal relation between human papillomavirus and cervical cancer. J Clin Pathol. 2002;55:244265.

5. Bosch FX, Manos MM, Muñoz N, et al. Prevalence of human papillomavirus in cervical cancer: a worldwide perspective. J Natl Cancer Inst. 1995;87:796-802.

6. Brower V. Connecting viruses to cancer: How research moves from association to causation. J Natl Cancer Inst. 2004;96(4):256-257.

7. Dalstein V, Riethmuler D, Pretet JL, et al. Persistence and load of high-risk HPV are predictors for development of high-grade cervical lesions: A longitudinal French cohort study. Int J Cancer. 2003;106:396-403.

8. Harris TG, Kulasingam SL, Kiviat NB, et al. Cigarette smoking, oncogenic human papilloomavirus, Ki-67 antigen, and cervical intraepithelial neoplasia. $\mathrm{Am}$ J Epidemiol. 2003;159(9):834-842.

9. Munoz N, Bosch FX, de Sanjose S, et al. Risk factors for cervical intraepithelial neoplasia grade III carcinoma in situ in Spain and Columbia. Cancer Epidemiol Biomarkers Prev. 1993;2:423-431.

10. Slama J, Fischerova D, Pinkavova I, Zikan M, Cibula D. Human papillomavirus DNA presences in pelvic lymph nodes in cervical cancer. Int J Gynecol Cancer. 2010;20(1):126-132.

11. Schiech L. HPV related cancer an equal opportunity danger. Nursing 2010. 2010;40(10):23-28.

12. Renshaw AA. Measuring sensitivity in gynecologic cytology. Cancer. 2002;96(4):210-217.

13. Cox JT. Liquid-based cytology: evaluation of effectiveness, cost-effectiveness, and application to practice. J Natl Compr Canc Netw. 2004;2(6):597-611.

14. Uyar DS, Eltabbakh GH, Mount SL. Positive predictive value of liquid-based and conventional cervical Papanicolaou smears reported as malignant. Gynecol Oncol. 2003;89:227-232. 
15. Harris TG, Miller L, Ulasingam SL, et al. Depot-medroxyprogesterone acetate and combined oral contraceptive used and cervical neoplasia among women with oncogenic human papillomavirus infection. Am J Obstet Gynecol. 2009;489(e1):489.e481-489.e488.

16. Kaptain S, Bloom L, Weir MM. Hormonal effects of depo-provera in cervical smears. Cancer. 2002;96(2):74-82.

17. Valente PT, Schantz HD, Trabal JF. Cytologic changes in cervical smears associated with prolonged use of depot medroxyprogesterone acetate. Cancer Cytopathol. 1998;84(6):328-334.

18. Risser MN, Murpy M. Oral contraceptives and cervical cancer. Nurs Pract. 2003;28(1):66.

19. Culwell KR, Feinglass J. Changes in prescription contraceptive use, 1995-2002: The effect of insurance status. Obstet Gynecol. 2007;110( 6 ):1371-1378.

20. Littlecrow-Russell S. Time to take a critical look at Depo-Provera: Hampshire College Population and Development Progam;2000.

21. Davidson $\mathrm{D}, \mathrm{Wu} \mathrm{T}$. Underestimation of cervical lesion severity in cytology specimens from patients receiving longterm antifertility treatment. Acta Cytol. 1997;41:1566A.

22. Freeman-Wang T, Walker P, Linehan J, Coffey C, Glasser B, Sherr L. Anxiety levels in women attending colposcopy clinics for treatment for cervical intraepithelial neoplasia: A randomised trial of written and video information. Bri J Obstet Gynecol. 2001;108(5):482-484.

23. Hellsten C, Sjostrom K, Lindqvist P. A prospective Swedish cohort study on psychosocial factors influencing anxiety in women referred for colposcopy. Bri $J$ Obstet Gynecol. 2007;114(1):32-38.

24. Hellsten C, Sjostrom K, Lindqvist P. A longitudinal 2-year follow-up of quality of life in women referred for colposcopy after an abnormal cervical smear. Reprod Biol. 2009;147(2):221-225.

25. Guarisi R, Sarian LO, Hammes LS, et al. Smoking worsens the prognosis of mild abnormalities in cervical cytology. Acta Obstet Gynecol Scand. 2009;88(5):514520.

26. U.S. Census Bureau. State and county quickfacts. Davidson County, TN: U.S. Census Bureau; 2011.

27. Tennessee Department of Health Office of Policy Planning and Assessment. Prevalence of tobacco use in Tennessee, 1997-2007. In: Health TDo, ed. Nashville, TN: Tennessee Department of Health; 2008.

28. Sarian LO, Hammes LS, Longatto-Filho A, et al. Increased risk of oncogenic human papillomavirus infections and incident high-grade cervical intraepithelial neoplasia among smokers: Experience from the Latin American screening study. Sex Transm Dis. 2009;36(4):241-248. 
29. Thomas CL, ed Taber's Cyclopedic Medical Dictionary. 14th ed. Philadelphia, PA: F.A. Dais Company; 1981.

30. Frye CF. An overview of oral contraceptives mechanism of action and clinical use. Neurology. 2006;66 (Supp1 3):S29-S36.

31. Ferris DG, Cox JT, O'Connor DM, Wright VC, Foerster J. Modern Colposcopy. 2nd ed. Dubuque, IA: Kendall/Hunt Publishing; 2004.

32. Wiley D, Masongsong E. Human papillomavirus: The burden of infection. Obstet Gynecol Survey, Suppl. 2006;61(6):S3-S14.

33. Meyer T, Arndt R, Beckmann ER, Padberg B, Christophers E, Stockfleth E. Distribution of HPV 53, HPV 73 and CP8304 in genital epithelial lesions with different grades of dysplasia. Int J Cancer. 2001;11:198-204.

34. Cromer BA, Smith RD, Dwyer J, Blair JA, Brown RT. A prospective study of adolescents who choose among levonorgestrel implant (Norplant), medroxyprogesterone acetate (Depo-Provera), or the combined oral contraceptive pill as contraception. Pediatrics. 1994;94(5):687-694.

35. Dehlendorf C, Ruskin R, Grumbach K, et al. Recommendations for intrauterine contraception: A randomized trial of the effects of patients' race/ethnicity and socioeconomic status. Am J Obstet Gynecol. 2010;203(4):319.e311-319.e318.

36. Clark MK, Stockdale CK, Railsback L, Nichols S. Differences in cervical cytologic and histologic findings between women using depotmedroxyprogesterone acetate and oral contraceptives. J Lower Genital Tract Dis. 2011;15(3):219-233.

37. Stafl A, Mattingly RF. Colposcopic diagnosis of cervical neoplasia. Obstet Gynecol. 1973;41(2):168-176.

38. Nucci MR, Crum CP. Redefining early cervical neoplasia: recent progress. $A d v$ Anat Pathol. 2007;14(1):1-10.

39. Moore KN, Bannon RJ, Lanneau GS, Zuna RE, Walker JL, Gold MA. Cervical dysplasia among women over 35 years of age. Am J Obstet Gynecol. 2008;199:471.e471-471.e475.

40. Gigi-Leiter O, Geiger B, Levy R, Czernobilsky B. Cytokeratin expression in squamous metaplasia of the human uterine cervix. Differentiation. 1986;31:191205.

41. Moscick AB, Burt VG, Knowitz S, Darragh T, Shiboski S. The significance of squamous metaplasia in the development of low grade squamous intraepithelial lesions in young women. Cancer. 1999;85:1139-1144.

42. Colgan TJ, Lickrish GM. The topography and invasive potential of cervical adenocarcinoma in situ, with and without associated squamous dysplasia. Gynecol Oncol. 1990;36:246-249. 
43. Tase T, Okagaki T, Clark BA, et al. Human papillomavirus DNA in glandular dysplasia and microglandular hyperplasia: Presumed precursors of adenocarcinoma of the cervix uteri. Gynecology. 1989; 73:1005-1008.

44. Schnatz PF, Guile M, O’Sullivan DM, Sorosky JI. Clinical significance of atypical glandular cells on cervical cytology. Obstet Gynecol. 2006;107(3):701708.

45. Huntington J, Oliver LM, St Anna L. What is the best approach for patients with ASCUS detected on Pap smear? J Fam Prac. 2004;53(3):240-241.

46. Centers for Disease Control. Genital HPV Infection - Fact Sheet. 2011; http://www.cdc.gov/std/hpv/stdfact-hpv.htm. Accessed 11/26/11.

47. Hellberg D, Stendahl U. The biological role of smoking, oral contraceptive use and endogenous sexual steroid hormones in invasive squamous epithelial cervical cancer. Anticancer Res. 2005;25(4):3041-3046.

48. Roteli-Martins CM, Panetta K, Ferreira Alves VA, Coelho Siqueira SA, Syrjänen KJ, Mauricette Derchain SF. Cigarette smoking and high-risk HPV DNA as predisposing factors for high-grade cervical intraepithelial neoplasia (CIN) in young Brazilian women. Acta Obstet Gynecol Scand. 1998;77(6):1427-1431.

49. Gupta S, Sodhani P, Sharma A, et al. Prevalence of high risk human papillomavirus type 16/18 infection among women with normal cytology: Risk factor analysis and implications for screening and prophylaxis. Cytopathology. 2009;20(4):249-255.

50. Hellberg D, Nilsson S, Haley NJ, Hoffman D, Wynder E. Smoking and cervical intraepithelial neoplasia: Nicotine and cotinine in serum and cervical mucus in smokers and nonsmokers. Am J Obstet Gynecol. 1988;158:910-913.

51. Huang YK, You SL, Yuan CC, et al. Long-term outcomes of high-risk human papillomavirus infection support a long interval of cervical cancer screening. $\mathrm{Br} J$ Cancer. 2008;98(5):863-869.

52. Ho CM, Lee BH, Chang SF, et al. Type-specific human papillomavirus oncogene messenger RNA levels correlate with the severity of cervical neoplasia. Int $J$ Cancer. 2009; 127:622-632.

53. Melikiana AA, Sun P, Prokopczyk B, et al. Identification of benzo[a]pyrene metabolites in cervical mucus and DNA adducts in cervical tissues in humans by gas chromatography-mass spectrometry. Cancer Lett. 1999;146(2):127-134.

54. Bedell MA, Hudson JB, Golub TR, et al. Amplification of human papillomavirus genomes in vitro is dependent on epithelial differentiation. $J$ Virol. 1991;65(5):2254-2260.

55. Stanley MA, Browne HM, Appleby M, Minson AC. Properties of a nontumorigenic human cervical keratinocyte cell line. Int J Cancer. 1989;43(4):672676. 
56. Cheng S, Schmidt-Grimminger DC, Murant T, Broker TR, Chow LT.

Differentiation-dependent up-regulation of the human papillomavirus E7 gene reactivates cellular DNA replication in suprabasal differentiated keratinocytes. Genes Dev. 1995;9(19):2335-2349.

57. MacLaughlan SD, Lachance JA, Gjelsvik A. Correlation between smoking status and cervical cancer screening: A cross-sectional study. J Lower Genital Tract Dis. 2011;15(2):114-119.

58. Coughlin SS, Uhler RJ, Hall HA, Briss PA. Non-adherence to breast and cervical cancer screening: What are the linkages to chronic disease risk? Prevention of Chronic Disease. Vol 1. Atlanta, GA: Centers for Disease Control; 2004:A04.

59. Dürst M, Glitz D, Schneider A, zur Hausen H. Human papillomavirus type 16 (HPV 16) gene expression and DNA replication in cervical neoplasia: Analysis by in situ hybridization. Virology. 1992;189(1):132-140.

60. Higgins GD, Uzelin DM, Phillips GE, McEvoy P, Marin R, Burrell CJ. Transcription patterns of human papillomavirus type 16 in genital intraepithelial neoplasia: Evidence for promoter usage within the E7 open reading frame during epithelial differentiation. J Gen Virol. 1992;73(8):2047-2057.

61. Stoler MH, Rhodes CR, Whitbeck A, Wolinsky SM, Chow LT, Broker TR. Human papillomavirus type 16 and 18 gene expression in cervical neoplasias. Hum Pathol. 1992;23(2):117-128.

62. Solomon D, Schiffman M, Tarone R. ASCUS LSIL triage study (ALTS) conclusions reaffirmed: Response to a November 2001 commentary. Obstet Gynecol. 2002;99(4):671-674.

63. Ferenczy A. Viral testing for genital human papillomavirus infections: Recent progress and clinical potentials. Int J Gynecol Cancer. 1995;5(5):321-328.

64. Kurman RJ, Henson DE, Herbst AL, et al. Interim guidelines for management of abnormal cervical cytology. JAMA. 1994;271(23):1866-1869.

65. Voorjis PG. Benign proliferative reactions, intraepithelial lesions of the cervix. In: Kurman RJ, ed. Blaustein's Pathology of the Female Genital Tract. New York: Springer-Verlag; 1994:229-232.

66. Stoler M, Schiffman M. Atypical squamous cells of undetermined significancelow-grade squamous intraepithelial lesion triage study (ALTS) group.

Interobserver reproducibility of cervical cytologic and histologic interpretations: realistic estimates from the Ascus-LSIL Triage Study. JAMA. 2001;285(11):15001505.

67. Ostör A. Natural history of cervical intraepithelial neoplasia: A critical review. Ing J Gynecol Pathol. 1993;12(2):186-192.

68. Wright TC, Kurman R, Ferenczy A. Precancerous lesions of the cervix. In: Kurman RJ, ed. Blaustein's Pathology of the Female Genital Tract. New York: Springer-Verlag; 1994:245-249. 
69. Ostbye T, Greenberg GN, Taylor DH, Lee AMM. Screening mammography and Pap tests among older American women 1996-2000: Results from the Health and Retirement Study (HRS) and Asset and Health Dynamics Among the Oldest Old (AHEAD). Annals of Family Medicine. 2003;1:209-217.

70. $\mathrm{Ng}$ ABP, Reagan JW, Lindner EA. The cellular manifestations of microinvasive squamous cell carcinoma of the uterine cervix. Obstet Gynecol Surv. 1972;27(7):529-531.

71. Lee KR, Ashfaq R, Birdsong GG, Corkill ME, McIntosh KM, Inhorn SL. Comparison of conventional Papanicolaou smears and a fluid-based, thin-layer system for cervical cancer screening. Obstet Gynecol. 1997;90(2):278-284.

72. Alli PM, Ali SZ. Atypical squamous cells of undetermined significance rule out high-grade squamous intraepithelial lesion: Cytopathologic characteristics and clinical correlates. Diagn Cytopathol. 2003;28(6):308-312.

73. Meisels A, Fortin R. Condylomatous lesions of the cervix and vagina: Cytologic patterns. Obstet Gynecol Surv. 1976;32(5):322-324.

74. Richert RM. Cervical Intraepithelial neoplasia: A review. In: Somers SC, ed. Pathology Annual. New York: Appleton-Century-Crofts; 1973:301-328.

75. Scully RE, Bonfiglio TA, Silverberg SG. Histologic Typing of Female Genital Tract Tumours: World Health Organization International Histological Classification of Tumours. 2nd ed. New York: Springer-Verlag; 1994.

76. Longatto-Filho A, Hammes LS, Sarian LO, et al. Hormonal contraceptives and the length of their use are not independent risk factors for high-risk HPV infections or high-grade CIN. Gynecol Obstet Invest. 2011;71(2):93-103.

77. Morrison CS, Bright P, Wong EL, et al. Hormonal contraceptive use, cervical ectopy, and the acquisition of cervical infections. Sex Transm Dis. 2004;31(9):561-567.

78. Salazar EL, Sojo-Aranda I, Lopez R, Salcedo M. The evidence for an etiological relationship between oral contraceptive use and dysplastic change in cervical tissue. Gynecol Endocrinol. 2001;15(1):23-28.

79. Vallès X, Murga GB, Hernández G, et al. High prevalence of human papillomavirus infection in the female population of Guatemala. Int $J$ Cancer. 2009;125:1161-1167.

80. McIntyre K, Castle PE, Guido R, Schiffman M, Wheeler CM, The ALTS group. Smoking is a risk factor for cervical intraepithelial neoplasia grade 3 among oncogenic human papillomavirus DNA-positive women with equivocal or mildly abnormal cytology. Cancer Epidemiol Biomarkers Prev. 2005;14:1165-1170.

81. Clifford GM, Gallus S, Herrero R, et al. Worldwide distribution of human papillomavirus types in cytologically normal women in the International Agency for Research on Cancer HPV prevalence surveys: A pooled analysis. Lancet. 2005; Volume 366(9490):991-998. 
82. Mosher W, Jones J. Use of contraception in the United States: 1982-2008. Vital and Health Statistics 2010; http://www.ncbi.nlm.nih.gov/pubmed/20939159, 2011. Accessed 8/11/2011

83. Moreno V, Bosch FX, Muñoz N, et al. Effect of oral contraceptives on risk of cervical cancer in women with human papillomavirus infection: the IARC multicentric case-control study. Lancet. 2002;359(9312):1085-1092.

84. Franco EL, Schlecht NF, Saslow D. The epidemiology of cervical cancer. Cancer J. 2003;9(5):348-359.

85. Green J, Berrington de Gonzalez A, Smith JS, et al. Human papillomavirus infection and use of oral contraceptives. Br J Cancer. 2003;88(11):1713-1720.

86. Smith JS, Green J, de Gonzalez AB, et al. Cervical cancer and use of hormonal contraceptives: A systematic review. Lancet. 2003;361(9364):1159-1167.

87. Bosch FX, Muñoz N, de Sanjosé S, et al. Risk factors for cervical cancer in Colombia and Spain. Int J Cancer. 1992;52:750-758.

88. Delavande A. Pill, patch, or shot? Subjective expectations and birth control choice. Int Econom Rev. 2008;49(3):999-1042.

89. Pett $\mathrm{M}$, Coleman N. Integration of high-risk human papillomavirus: A key event in cervical carcinogenesis? J Pathol. 2007;212(4):356-367.

90. 2001-2007 Committee on Women Population and the Environment. Depo Provera Fact Sheet. 2007; http://www.cwpe.org/node/185. Accessed 10/01/2011.

91. Hubacher D, Lara-Ricalde R, Taylor DJ, Guerra-Infante F, Guzman-Rodriguez R. Use of copper intrauterine devices and the risk of tubal infertility among nulligravid women. $N$ Engl J Med. 2001;345:561-567.

92. Planned Parenthood of America. "The IUD at a glance." Q\&A with Dr. Cullins. 2011; http://www.plannedparenthood.org/health-topics/birth-control/iud4245.htm. Accessed 11/10/11.

93. Oberle MW, Rosero-Bixby L, Irwin KL, et al. Cervical cancer risk and use of depot-medroxyprogesterone acetate in Costa Rica. Int J Epidemiol. December 1, 1988 1988;17(4):718-723.

94. Bayer Corporation. Mirena. 2011; http://mirena-us.com/index.jsp. Accessed $11 / 10 / 2011$.

95. McFarlane-Anderson N, Bazuaye P, Jackson M, Smikle M, Fletcher H. Cervical dysplasia and cancer and the use of hormonal contraceptives in Jamaican women. BMC Women's Health. 2008;8:9.

96. Bonte J, Decoster J, Ide P. Vaginal cytologic evaluation as a practical link between hormone blood levels and tumor hormone dependency in exclusive medroxyprogesterone treatment of recurrent or metastatic endometrial adenocarcinoma. Acta Cytol. 1977;21(2):218-224. 
97. Fiorella RM, Brasfield K, Duney S, McGuire S, Poole S, Kragel P. Cervical cytology associated with medroxyprogesterone acetate contraception. Acta Cytol. 1995;39:981A.

98. Van Der Laak J, De Bie L, De Leeuw H, De Wilde P, Hanselaar A. The effect of Replens ${ }^{\circledR}$ on vaginal cytology in the treatment of postmenopausal atrophy: Cytomorphology versus computerised cytometry. J Clin Pathol. 2002;55(6):446451.

99. Turbat-Herrera EA, Knowles K. Cytology: Screening or diagnostic tool? Hum Pathol. 1998;29(12):1356-1366.

100. Zhu W, Wilbur DC. Squamous intraepithelial lesions following diagnoses of atypical squamous cells of undetermined significance (ASCUS) in progesteronetreated women: Comparison with an untreated control group. Acta Cytol. 1998;42:1224A-1227A.

101. Smith JS, Herrero R, Bosetti C, et al. Herpes Simplex Virus-2 as a human papillomavirus cofactor in ethe etiology of invasive cervical cancer. $J$ Natl Cancer Inst. 2002;94(21):1604-1613.

102. De Vuyst H, Clifford GM, Nascimento MC, Madeleine MM, Franceschi S. Prevalence and type distribution of human papillomavirus in carcinoma and intraepithelial neoplasia of the vulva, vagina and anus: A meta-analysis. Int $J$ Cancer. 2008;124:1626-1636.

103. Darwish A, Labeeb S, Galal M, Rashad H, Hassan S. Cervical changes associated with progestagen-only contraceptives: A team approach. Contraception. 2004;69(2):121-127.

104. Hoekstra AV, Kosinski A, Huh WK. Hormonal contraception and false-positive cervical cytology: Is there and association? J Lower Genital Tract Dis. 2006;10(2):102-106.

105. Drejet A, Kellogg M, Riley E. Epithelial cell abnormality in the Depo-Provera patient: A diagnostic pitfall. Acta Cytol. 1998;42(5):1235.

106. International Business Machines (IBM). SPSS Professional, 19. 2011; http://www-01.ibm.com/software/analytics/spss/products/statistics/stats-pro/. Accessed 6/1/11.

107. Centers for Disease Control and Prevention. Adult cigarette smoking in the United States: Current estimate. Smoking and Tobacco Use 2011; http://www.cdc.gov/tobacco/data_statistics/fact_sheets/adult_data/cig_smoking/ index.htm. Accessed 11/5/11.

108. Davis KC, Nonnemaker JM, Asfaw HA, Vallone DM. Racial/ethnic differences in perceived smoking prevalence: Evidence from a national survey of teens. Int $J$ Environ Res Public Health. 2010;7(12):4152-4168.

109. Bachman JG, Wallace JM, Jr, O'Malley PM, Johnston LD, Kurth CL, Neighbors HW. Racial/Ethnic differences in smoking, drinking, and illicit drug use among American high school seniors, 1976-89. Am J Public Health. 1991;81(3):372-377. 
110. Wills TA, Cleary SD. The validity of self-reports of smoking: Analyses by race/ethnicity in a school sample of urban adolescents. Am J Public Health. 1997;87(1):56-61.

111. Graham H, Francis B, Inskip HM, Harman J, SWS Study Group. Socioeconomic lifecourse influences on women's smoking status in early adulthood. $J$ Epidemiol Community Health. 2006;60(3):228-233.

112. Higgins ST, Chilcoat HD. Women and smoking: An interdisciplinary examination of socioeconomic influences. Drug Alcohol Depend. 2009;104(Suppl 1):S1-S5.

113. Kim H, Clark PI. Cigarette smoking transition in females of low socioeconomic status: Impact of state, school, and individual factors. J Epidemiol Community Health. 2006;60(Suppl 2):ii13-ii19.

114. Capps NP, Stewart A, C. B. The interplay between secondhand cigarette smoke, genetics, and cervical cancer: A review of the literature. Biol Res Nurs. 2009;10 (4):392-399.

115. Cerqueira EM, Santoro CL, Donozo NF, et al. Genetic damage in exfoliated cells of the uterine cervix: Association and interaction between cigarette smoking and progression to malignant transformation? Acta Cytol. 1998;42(3):639-649.

116. Ferreraa A, Velemab JP, Figueroaa M, et al. Co-factors related to the causal relationship between human papillomavirus and invasive cervical cancer in Honduras. Int J Epidemiol. 2000;29(5):817-825.

117. Lindstrom A, Ekman K, Stendahl U, et al. LRIG1 and squamous epithelial uterine cervical cancer: Correlation to prognosis, other tumor markers, sex steroid hormones, and smoking. J Gynecol Cancer. 2007;18:312-317.

118. Velema JP, Ferrera A, Figueroa M, et al. Burning wood in the kitchen increases the risk of cervical neoplasia in HPV-infected women in Honduras. Int J Cancer. 2002;97:536-541.

119. Bartona SE, Jenkins D, Cuzick J, Maddox PH, Edwards R, Singer A. Effect of cigarette smoking on cervical epithelial immunity: A mechanism for neoplastic change? . Lancet. 1988;332(8612):652-654.

120. Morelli AE, Sananes C, Di Paola G, Paredes A, Fainboim L. Relationship between types of human papillomavirus and Langerhans' cells in cervical condyloma and intraepithelial neoplasia. Am J Clin Pathol. 1993;99:200-206.

121. Coker AL, Bond SM, Williams A, Gerasimova T, Pirisi L. Active and passive smoking, high-risk human papillomaviruses, and cervical neoplasia. Cancer Detect Prev. 2002;26:121-128.

122. Moscicki AB, Ma $Y$, Wibbelsman $C$, et al. Risks for cervical intraepithelial neoplasia 3 among adolescents and young women with abnormal cytology. Obstet Gynecol. 2008;112(6):1335-1342. 
123. Stanwood NL, Garrett JM, Konrad TR. Obstetrician-gynecologists and the intrauterine device: A survey of attitudes and practice. Obstet Gynecol. 2002;99(2):275-277.

124. Barbieri RL. We should encourage more women to use the modern IUD. $O B G$ Management. 2007;19(4):10-15.

125. DeMay RM. Cytopathology of false negative preceeding cervical carcinoma. Am J Obstet Gynecol. 1996;175(4):1110-1113.

126. Pregler J, Freund KM, Kleinman M, et al. The heart truth professional education campaign on women and heart disease: Needs assessment and evaluation results. $J$ Women's Health. 2009;18(10):1541-1547.

127. Stampfer J, Hu FB, Manson JE, Rimm EB, Willett WC. Primary prevention of coronary heart disease in women through diet and lifestyle. $N$ Engl J Med. 2000;343:16-22.

128. Science Daily. Young women unfamiliar with safety, effectiveness of IUD. 2006; http://www.sciencedaily.com/releases/2006/12/061216104722.htm. Accessed $11 / 26 / 11$. 


\section{VITA}

Michelle Collins was born in 1964 in Rockford, Illinois. She received a diploma of Nursing from Saint Anthony School of Nursing and a Bachelor of Science in Nursing from Rockford College. She received a Master of Science in Nursing with emphasis in Nurse-Midwifery from Marquette University and was certified as a nurse-midwife in 2002. She completed a colposcopy mentorship program through the American Society of Colposcopy and Cervical Pathology in 2003 and continues to serve as a mentor for novice colposcopists through this organization.

She is actively involved locally, regionally, and nationally in professional organizations, serving on multiple committees. She was accepted to The University of Tennessee Health Science Center to pursue a PhD in Nursing in 2009. Her research in the $\mathrm{PhD}$ program focused on accuracy of cytologic interpretation in women using progesterone only contraception. She has presented numerous times locally, regionally, and nationally at nursing conferences. She has over 26 years of experience in the field of nursing, having been a nurse, certified nurse-midwife, and educator and is currently an Assistant Professor of Nursing at Vanderbilt University in the Nurse Midwifery program. 